J. Chem. Phys., in press.

Final author version

Oct. 24, 2006

\title{
A New Local Density Functional for Main Group Thermochemistry, Transition Metal Bonding, Thermochemical Kinetics, and Noncovalent Interactions
}

\author{
Yan Zhao and Donald G. Truhlar \\ Department of Chemistry and Supercomputing Institute \\ University of Minnesota, 207 Pleasant Street S.E. \\ Minneapolis, MN 55455-0431
}

\begin{abstract}
.
We present a new local density functional, called M06-L, for main-group and transition element thermochemistry, thermochemical kinetics, and noncovalent interactions. The functional is designed to capture the main dependence of the exchangecorrelation energy on local spin density, spin density gradient, and spin kinetic energy density, and it is parametrized to satisfy the uniform-electron-gas limit and to have good performance for both main-group chemistry and transition metal chemistry. The M06-L functional and 14 other functionals have been comparatively assessed against 22 energetic databases. Among the tested functionals, which include the popular B3LYP, BLYP, and BP86 functionals as well as our previous M05 functional, the M06-L functional gives the best overall performance for a combination of main group thermochemistry, thermochemical kinetics, and organometallic, inorganometallic, biological, and noncovalent interactions. It is also does very well for predicting geometries and vibrational frequencies. Because of the computational advantages of local functionals, the present functional should be very useful for many applications in chemistry, especially for simulations on moderate-sized and large systems and when long time scales must be addressed.
\end{abstract}




\section{INTRODUCTION}

In the early days of density functional theory, ${ }^{1}$ all density functionals were local. Local functionals may depend on the local spin density, ${ }^{2,3}$ its gradient ${ }^{4-9}$ or Laplacian, ${ }^{10}$ or even spin kinetic energy density approximated in terms of the kinetic energy of KohnSham spin orbitals. ${ }^{11-13}$ Unfortunately functionals depending on the gradient of the spin density were sometimes called nonlocal, but that semantic error appears to be disappearing. More recently, nonlocal density functionals have been widely employed, and in many cases they greatly improve the accuracy. ${ }^{14-17}$ The present article returns to the formulation of local density functionals.

It is important to clarify the significance of local density functionals. Some researchers have voiced the opinion that nonlocal density functionals are to be tolerated as an interim "fix" until the true density functional is derived/discovered/developed. This is a misunderstanding. The theorem ${ }^{18}$ that exact density functionals exist does not apply to local density functionals; thus we must allow a density functional to be nonlocal if it is to be exact. ${ }^{19,20}$ Nonlocal density functionals include hybrid functionals that depend on Hartree-Fock exchange. ${ }^{14}$ Thus local functionals are important not because they somehow represent a more theoretically justified solution. Rather they are important for practical reasons because calculations on large complex systems may employ specialized algorithms (including density fitting, also called resolution of the identity) that are tens or hundreds of times faster if one employs local density functionals than if one employs nonlocal ones. ${ }^{21-30}$ For example, we found that a single-point energy calculation for a

$\mathrm{C}_{104} \mathrm{H}_{30} \mathrm{~N}_{4}$ fullerene-porphyrin complex ${ }^{31}$ with a local functional employing density fitting is 15 times faster (17 hours vs. 250 hours) than a hybrid density functional 
calculation on the same system (using GAUSSIAN0 $3^{32}$ ). Furthermore, calculations are impractical for many solids when Hartree-Fock exchange is included, ${ }^{33}$ unless some special techniques ${ }^{34-37}$ are employed.

A second reason to study local density functionals is their usefulness for modeling the bonding of metallic elements. Two recent systematic studies of highly unsaturated systems containing metal atoms, one for metal-metal bonds ${ }^{38}$ and one for metal-ligand bonds,${ }^{39}$ have shown that most functionals with more than about $10 \%$ Hartree-Fock exchange fail badly for a large number of bonds involving transition metals, which is understandable in that the density-based exchange functionals do a better job than Hartree-Fock exchange in accounting for static correlation. ${ }^{9,40-43}$ Even more recently we have presented a new functiona ${ }^{44}$ called M05, that performs well for such cases even with $28 \%$ Hartree-Fock exchange and also performs well for main group chemistry, barrier heights, and non-covalent interactions. Nevertheless, we are still interested in local density functionals because of their cost advantages discussed in the previous paragraph.

In the present article, we present a local functional that has better general performance than the most popular hybrid functional, B3LYP. The new functional is called M06-L. We assess this new functional by applying it, along with eleven previous local functionals (BP86, ${ }^{5,7} \mathrm{BLYP},{ }^{7,8} \mathrm{BB} 95,{ }^{7,11} \mathrm{G} 96 \mathrm{LYP},{ }^{8,45} \mathrm{PBE},{ }^{46} \mathrm{mPWPW},{ }^{16,47} \mathrm{VSXC},{ }^{12}$ $\mathrm{HCTH},{ }^{48} \mathrm{OLYP},{ }^{41} \tau$-HCTH,${ }^{49}$ and $\left.\mathrm{TPSS}^{13}\right)$ and three previous nonlocal functionals (B3LYP, ${ }^{7,14,50} \mathrm{TPSSh}^{51}$ and $\mathrm{M} 05^{44}$ ), to the data in 22 diverse databases. In fact the average performance of the M06-L functional over the 22 energetic databases considered here is better than that of any local or hybrid functional that we know. 
Most of the databases used in the present work have been introduced and described in previous work. One new database introduced here is a database of five metal-atom excitation energies containing two main group neutral metals, two neutral transition metals, and one transition metal cation. The addition of this data set is prompted by the increasing attention being paid by many workers to the relative energies of spin states of transition metal systems because of the importance of spin states for structures, properties, and chemical reactivities of organometallic complexes and for functional nanotechnology. ${ }^{52-62}$ Holthausen made a systematic study ${ }^{63}$ of the ability of density functionals to predict $3 d-4 s$ excitation energies in transition metal cations and found that some functionals, even though performing well for main group atomization energies, show large errors for transition metal atomic excitation energies. Because we seek a functional that is accurate for both main-group and transition metal chemistry, our small database has both types of atoms. We note that our transition metal excitation energy comparisons take account of scalar relativistic effects, ${ }^{64}$ whereas those of Holthausen do not, even though such effects are sometimes large.

The paper is organized as follows. Section 2 presents our databases. Section 3 gives computational details. Section 4 discusses the theory and parametrization of the new functionals. Section 5 presents results and discussion, including test for energies, geometries, and frequencies not used in training, and Section 6 concludes the paper.

\section{ENERGETIC DATABASES}

Our general notation for databases is $\mathrm{XN} / \mathrm{V}$, where $\mathrm{X}$ is an acronym for the type of data, $N$ is the number of data, and $\mathrm{V}$ is a version number (sometimes omitted if there 
has only been one version). The reason for version numbers is that historically we have sometimes corrected (if possible) or eliminated data whose reliability has been disproved or credibly challenged. All data in Subsections II.A through II.H are pure electronic energies, i.e., zero-point energies and thermal vibrational-rotational energies have been

removed by methods discussed previously, ${ }^{17,65-68}$ but nuclear repulsion is included. Since the databases are based on experimental or accurate data, the values in our database correspond to relativistic values. Thus our calculations must include relativistic corrections as well, where these are not negligible; this is discussed in Section III.B.

\section{II.A. MGAE109/05 test set}

The MGAE109/05 test set ${ }^{17}$ consists of 109 atomization energies (AEs) for main group compounds. We always give the mean errors in atomization energies on a per bond basis because that makes comparison between different test sets more portable. In the past, as some workers increased the size of their test sets, they tended to add larger molecules, and the resulting increase in mean errors due to increasing the average number of bonds could not be distinguished from the increase in mean errors due to the added diversity of the test molecules. To make it possible for readers to compare other workers' values to our mean errors on a per bond basis, we always compute the mean errors in atomization energies by computing the mean error per molecule and then dividing by the average number of bonds per molecule in the test set. The latter value is 4.71 for MGAE109/05.

\section{II.B. Ionization potential, electron affinity, and proton affinity test sets}

The zero-point-exclusive ionization potential (IP) and electron affinity (EA) test sets are called IP13/3 and EA13/3, respectively, and they have been explained and 
employed in our previous papers. ${ }^{17,44,65,68}$ PA8 is a database of eight zero-pointexclusive proton affinities. ${ }^{69}$ These three databases involve only small molecules and atoms.

\section{II.C. Barrier height databases}

The HTBH38/04 database contains 38 transition state barrier heights for 19 hydrogen transfer (HT) reactions, eighteen of which involve radicals as reactant and product. They are taken from previous papers. ${ }^{17,67,70}$ NHTBH38/04 consists of three databases containing 38 transition state barrier heights for non-hydrogen-transfer (NHT) reactions, and these databases have been presented in a previous paper. ${ }^{70}$ The individual databases contain 12 barrier heights for heavy-atom transfer reactions, 16 barrier heights for nucleophilic substitution (NS) reactions, and 10 barrier heights for non-NS unimolecular and association reactions.

\section{II.D. Noncovalent interaction databases}

Recently we developed several databases, in particular, HB6/04, ${ }^{71} \mathrm{CT} 7 / 04,{ }^{71}$ DI6/04, ${ }^{71}$ WI $7 / 05,{ }^{68}$ and PPS $5 / 05,{ }^{68}$ for various kinds of noncovalent interactions. HB6/04 is a hydrogen bond database that consists of the equilibrium binding energies of six hydrogen bonding dimers. The CT7/04 database consists of binding energies of seven charge transfer complexes. The DI6/04 database contains the binding energies of six dipole interaction complexes. The WI7/05 database consists of the binding energies of seven weak interaction complexes, all of which are bound by dispersion interactions. The PPS5/05 database consists of binding energies of five $\pi-\pi$ stacking complexes. We also test the density functionals against a benchmark database of 22 noncovalent interactions of biological importance; it is called S22, and it was developed by Jurecka et al. ${ }^{72}$ The 
S22 database includes both small and large systems, with the largest system containing 30 atoms.

\section{II.E. Transition metal dimer and transition metal-ligand databases}

We employ three databases involving molecules containing transition metals. $\mathrm{One}^{38}$ is for atomization energies of transition metal-transition metal dimers, and it is called the TMAE9/05 database; it contains the bond energies of $\mathrm{Ag}_{2}, \mathrm{Cr}_{2}, \mathrm{CuAg}, \mathrm{Cu}_{2}$, $\mathrm{Mo}_{2}, \mathrm{Ni}_{2}, \mathrm{~V}_{2}, \mathrm{ZrV}$, and $\mathrm{Zr}_{2}$. The other, ${ }^{39}$ called MLBE21/05, is for the metal-ligand bond energies in organometallic and inorganometallic complexes, and it contains 21 metalligand bond energies. We also test the density functionals against a benchmark database of 18 reaction energies involving $3 d$ transition metals; ${ }^{73}$ we called it $3 \mathrm{dTMRE} 18 / 06$, and it was developed by Furche and Perdew. ${ }^{74}$

\section{II.F. Alkyl bond dissociation energy (ABDE) database}

The next database contains four R-X bond dissociation energies $D_{\mathrm{e}}(\mathrm{R}=$ methyl and isopropyl; $\mathrm{X}=\mathrm{CH}_{3}$ and $\mathrm{OCH}_{3}$ ) and is called the ABDE4/05 database. The reference $D_{0}$ values are taken from a recent paper by Izgorodina et al, ${ }^{75}$ and we used the B3LYP/6$31 \mathrm{G}(\mathrm{d})$ zero-point vibrational energies scaled with a scale factor of $0.9806^{76}$ to obtain the accurate $D_{\mathrm{e}}$ values.

\section{II.G. $\pi$-system databases}

We employ three databases for $\pi$ systems, namely, $\pi \mathrm{IE} 3 / 06, \mathrm{PA}-\mathrm{CP} 5 / 06$, and PASB5/06. The $\pi \mathrm{IE} 3 / 06$ database contains three isomeric energy differences between allene and propyne as well as higher homologs (which correspond to cumulenes and polyynes). ${ }^{69,77} \mathrm{PA}-\mathrm{CP} 5 / 06$ is a database of the proton affinities of five conjugated polyenes. 
PA-SB5/06 is a database of the proton affinities of the five conjugated Schiff bases. All structures for these molecules are given in the Supporting Information. ${ }^{78}$

\section{II.H. Excitation energy database}

MAEE5 is a database of five metal-atom excitation energies containing two main group neutral metals (Be, Mg), two neutral transition metals ( $\mathrm{Mn}, \mathrm{Pd})$, and one transition metal cation $\left(\mathrm{Cu}^{+}\right)$. One reason that this database is small is to avoid the complication of mixed symmetry states that makes DFT predictions ambiguous for many open-shell transition metal atoms. ${ }^{63,73,74}$

\section{II.I. Bond length and frequency databases}

MGBL19 is a database of 19 experimental bond lengths of 15 small main-group molecules, and the experimental bond lengths are taken from a previous compilation by Hamprecht et. al. ${ }^{48}$ MLBL13/05 is a previously ${ }^{39}$ developed database of bond lengths of 13 metal-ligand compounds. F36/06 is a new database of 36 harmonic frequencies of the 13 molecules in a previous vibrational zero-point energy database (ZPE13/99). ${ }^{79,80}$ The experimental harmonic frequencies are taken from a previous compilation by Martin et

al. ${ }^{81}$ with one exception; since there is no reliable experimental harmonic frequency for the umbrella mode of the $\mathrm{NH}_{3}$ molecule, the best estimate for this mode is taken from a $\operatorname{CCSD}(\mathrm{T}) / \mathrm{cc}-\mathrm{pVQZ}$ calculation by Martin et al. ${ }^{81,82}$

\section{II.J. Supporting information}

The 3dTMRE18/06 database is completely described in Ref. ${ }^{74}$, and the ABDE4/06, MAEE5/06, MGBL19/06, and F36/06 databases will be presented below. The other 19 databases are given in Tables S1-S9 of Supporting Information. ${ }^{78}$ 


\section{COMPUTATIONAL METHODS}

\section{III.A. Geometries and basis sets}

All calculations for the AE6, MGAE109/05, IP13/3, EA13/3, HTBH38/04, and NHTBH38/05 databases are single-point calculations at QCISD/MG3 geometries, where QCISD is quadratic configuration interaction with single and double excitations, ${ }^{83}$ and MG3 is the modified ${ }^{84,85}$ G3 Large ${ }^{86}$ basis set. The MG3 basis set, ${ }^{84}$ also called G3LargeMP $2,{ }^{85}$ is the same as $6-311++\mathrm{G}(3 \mathrm{~d} 2 \mathrm{f}, 2 \mathrm{df}, 2 \mathrm{p})^{87,88}$ for H-Si, but improved ${ }^{86}$ for P-Ar. Geometries for the PA8/06 database are at the MP2(full)/6-31G(2df,p) level of theory.

Geometries for all molecules in the HB6/04, CT7/04, DI6/04, and WI7/05 noncovalent databases and the $\left(\mathrm{C}_{2} \mathrm{H}_{4}\right)_{2}$ and $\left(\mathrm{C}_{2} \mathrm{H}_{2}\right)_{2}$ dimers in the PPS5/05 database are optimized at the MC-QCISD/3 level, where MC-QCISD is the multi-coefficient QCISD method. ${ }^{66,89}$ The geometries for the benzene dimers in the PPS5/05 database are taken from Sinnokrot and Sherrill. ${ }^{90}$ The methods used to obtain geometries ${ }^{72}$ for the S22 database are specified in the Supporting Information, and all DFT calculations for the S22 database employ the $6-31+\mathrm{G}(\mathrm{d}, \mathrm{p})$ basis set.

Geometries for all molecules in the ABDE4/05 database are optimized at the B3LYP/6-31G(d) level, and they are given in the supporting information of a previous paper. $^{75}$ The $6-311+\mathrm{G}(3 \mathrm{df}, 2 \mathrm{p})$ basis set is used for the calculations of ABDEs; this choice is made for the purpose of comparison with the previous results.

Geometries for the molecules in the transition metal (TMAE9/05) and metalligand (MLBE21/05) bond energy databases are optimized consistently with each level of theory. We used the triple-zeta-quality TZQ basis $\operatorname{set}^{38}$ for the calculations on the 
molecules in these two databases. For the 3dTMRE18 database, we employed a quadruple-zeta-quality basis set, QZVP, developed by Weigend et al. ${ }^{91}$ and TPSS/QZVP geometries. $^{74}$

To test the functionals for the MAEE5 database, we employed the aug-cc-pVQZ basis set for $\mathrm{Be},{ }^{92} \mathrm{Mg},{ }^{92}$ and $\mathrm{Cu}^{+} .^{93}$ The basis set for $\mathrm{Mn}$ is the QZVP basis of Weigend et al., ${ }^{91}$ and that for Pd is the AVQZ basis set from Quintal et al. ${ }^{94}$

The MG3S basis set was employed for all the calculations on the MGBL19 and F36 databases.

\section{III.B. Relativistic effects}

In all cases, experimental data in the database are zero point exclusive, but (like all experimental data) they include relativistic effects. Since our DFT calculations are nonrelativistic, we must add relativistic effects to our computed Born-Oppenheimer energies in order to compare to experiment.

We divide relativistic effects into two types: scalar and vector. Scalar relativistic effects are generally very small for $\mathrm{H}-\mathrm{Cl}$, and these small effects are not included for main-group compounds in the present study. Scalar relativistic effects for systems in the 3dTMRE18/06 database were treated in exactly the same way as in Ref. ${ }^{74}$. We also include scalar relativistic effects for the excitation energies of $\mathrm{Mn}$ and $\mathrm{Cu}^{+}(\mathrm{MAEE5} / 06)$, and for the $4 d$ transition metals in the TMAE9/05, MLBE21/05, and MAEE5/06 databases. In most cases we take account of the scalar relativistic effect simply by using a relativistic effective core potential. For the $4 \mathrm{~d}$ metals, we use the relativistic effective core potential of Stevens et al. ${ }^{95}$ to replace the $1 s^{2} 2 s^{2} 2 p^{6} 3 s^{2} 3 p^{6} 3 d^{10}$ core, and the $4 s, 4 p$, $5 s$, and $4 d$ electrons are treated explicitly. For calculations on Pd atom, we employed the 
Stuttgart-Dresden relativistic effective core potential (MWB28) ${ }^{96}$ to replace the 28 core electrons, and the 18 valence electrons are treated explicitly. The scalar relativistic contributions for the excitation energy of the $\mathrm{Mn}$ and $\mathrm{Cu}^{+}$are taken from previous work. $^{64,97}$

The vector relativistic effect is included by adding spin-orbit coupling. In all of the calculations presented in this paper, the spin-orbit stabilization energy was added to atoms and open-shell molecules for which it is nonzero, as described previously. ${ }^{38,39,84}$ Note that spin-orbit coupling vanishes for closed-shell species, atoms in $S$ states, molecules in $\Sigma$ states, and singlet and doublet molecules in $A$ or $B$ states.

\section{III.C. Counterpoise correction}

For noncovalent complexes, we perform calculations with and without the counterpoise corrections $^{98,99}$ for basis set superposition error (BSSE).

\section{III.D. Software}

All calculations were performed with a locally modified version of the GAUSSIAN03 program. ${ }^{32}$

\section{THEORY AND PARAMETRIZATION}

In a recent review, ${ }^{33}$ Scuseria and Staroverov summarized the six strategies that have been widely employed for designing density functionals: (1) local density approximation (LDA); (2) density-gradient expansion (DGE); (3) constraint satisfaction; (4) modeling the exchange-correlation hole; (5) empirical fits; and (6) mixing HartreeFock and approximate DFT exchange. Our M05 ${ }^{44}$ and M05-2X $\mathrm{X}^{17}$ functionals were constructed with strategies (3), (5), and (6), and several of the key ideas were drawn from earlier work by Becke, Perdew, and others..$^{3,6,11,46,49,100-103}$ The M05 functional form is 
well suited to employing a high percentage of Hartree-Fock exchange. When we tried optimizing a local functional we found that the M05 functional form is not flexible enough to provide a local functional with broad accuracy. From the literature ${ }^{12,51,104}$ and from one of our previous assessments, ${ }^{105}$ one can see that the VSXC local functional ${ }^{12}$ performs very well for thermochemistry (and that will be reconfirmed in the present study). However, further studies ${ }^{106-108}$ also show that VSXC gives very discouraging performance for noncovalent interactions, and the barrier heights, although better than those from other local functionals, are not as good as one would desire. In contrast the M05-2X functional has excellent performance for noncovalent interactions and barrier heights, and M05 has reasonable performance for noncovalent interactions and barriers. These observations motivated us to combine the functional forms of VSXC and M05, and this combination provides the functional form adopted for M06-L. Interestingly, the VSXC functional (also called VS98) was developed using a density matrix expansion to model the exchange-correlation hole, a strategy of type (4). For the M06-L functional, we also enforce the uniform electron gas limit; therefore the M06-L functional is constructed based on strategies (3), (4) and (5). We note that the original parametrization of VSXC did not satisfy the uniform-electron gas (UEG) limit. The authors allowed this limit to be violated (by $\sim 5 \%$ for exchange, $67 \%$ for same-spin correlation, and 30\% for oppositespin correlation) to improve performance for atomic and molecular systems. Here we enforce this limit because our functional form is sufficiently flexible that enforcing it does not degrade performance for molecular systems.

The key issue in optimizing functionals is whether or not one has a functional form that captures the physically significant dependences. Experience, both ours and that 
of others, ${ }^{12,109}$ has shown that simply increasing the number of parameters does not necessarily yield a qualitatively more accurate functional or one that fits a more diverse set of data; the functional form is the key element.

Some preliminary studies showed that some terms in the VSXC functional cause an integration grid problem pointed by Johnson et al., ${ }^{106}$ so we set the coefficients for these terms to zero. Before we describe the details of the new functional, we define some basic variables and functions. The spin density is called $\rho_{\sigma}$, and the following equations define the reduced spin density gradient $x_{\sigma}$, and spin kinetic energy density $\tau_{\sigma}$, a working variable $z_{\sigma}$, and two working functions $\gamma$ and $h$ :

$$
\begin{gathered}
x_{\sigma}=\frac{\left|\nabla \rho_{\sigma}\right|}{\rho_{\sigma}^{4 / 3}} \quad \sigma=\alpha, \beta \\
\tau_{\sigma}=\frac{1}{2} \sum_{i}^{o c c u p}\left|\nabla \Psi_{i \sigma}\right|^{2} \\
z_{\sigma}=\frac{\tau_{\sigma}}{\rho_{\sigma}^{5 / 3}}-C_{F}, \quad C_{F}=\frac{3}{5}\left(6 \pi^{2}\right)^{2 / 3} \\
\gamma\left(x_{\sigma}, z_{\sigma}\right)=1+\alpha\left(x_{\sigma}^{2}+z_{\sigma}\right) \\
h\left(x_{\sigma}, z_{\sigma}\right)=\left(\frac{d_{0}}{\gamma\left(x_{\sigma}, z_{\sigma}\right)}+\frac{d_{1} x_{\sigma}^{2}+d_{2} z_{\sigma}}{\gamma_{\sigma}^{2}\left(x_{\sigma}, z_{\sigma}\right)}+\frac{d_{3} x_{\sigma}^{4}+d_{4} x_{\sigma}^{2} z_{\sigma}+d_{5} z_{\sigma}^{2}}{\gamma_{\sigma}^{3}\left(x_{\sigma}, z_{\sigma}\right)}\right)
\end{gathered}
$$

Note that $\sigma$ denotes the component of electron spin angular momentum and takes on two values: $\alpha(+1 / 2)$ and $\beta(-1 / 2)$.

It will be noticed in Sects. IV. A and IV. B that the new density functional depends on both $\tau_{\alpha}$ and $\tau_{\beta}$, not just on their sum. We use the standard language by which "spin" as an adjective means "spin-resolved". Thus we say that the functional depends on the spin 
kinetic energy densities rather than saying that it depends on the kinetic energy density, just as the functional depends on spin densities and their gradients, not just their sums.

The M06-L functional may be classified as a meta-generalized gradientapproximation (meta-GGA) where meta denotes dependence on spin kinetic energy density.

\section{IV.A. Meta-generalized gradient approximation (GGA) exchange functional}

The exchange functional used in the M05 functional ${ }^{44}$ was an extension of earlier functionals developed by Becke, Perdew, Burke, and Ernzerhof., $6,11,15,101,102$ The M05 functional form is well suited to employing a high percentage of Hartree-Fock exchange. In order to make a better local functional for the present work we added additional terms based on the relatively successful local exchange functional of Voorhis and Scuseria, ${ }^{12,110}$ which is based in part on earlier work by Negele and Vautherin. ${ }^{111}$ In particular the M06$\mathrm{L}$ exchange functional is given by

$$
E_{\mathrm{X}}^{\mathrm{M} 06-\mathrm{L}}=\sum_{\sigma} \int d r\left[F_{\mathrm{X} \sigma}^{\mathrm{PBE}}\left(\rho_{\sigma}, \nabla \rho_{\sigma}\right) f\left(w_{\sigma}\right)+\varepsilon_{\mathrm{X} \sigma}^{\mathrm{LSDA}} h_{\mathrm{X}}\left(x_{\sigma}, z_{\sigma}\right)\right]
$$

where $h_{\mathrm{X}}\left(x_{\sigma}, z_{\sigma}\right)$ is defined in eq. (5) (with $d_{5}=0$ in $\left.h_{\mathrm{X}}\left(x_{\sigma}, z_{\sigma}\right)\right), F_{\mathrm{X} \sigma}^{\mathrm{PBE}}\left(\rho_{\sigma}, \nabla \rho_{\sigma}\right)$ is the exchange energy density of the $\mathrm{PBE}^{46}$ exchange model, $\varepsilon_{\mathrm{X} \sigma}^{\mathrm{LSDA}}$ is the local spin density approximation for exchange

$$
\varepsilon_{\mathrm{X} \sigma}^{L S D A}=\frac{3}{2}\left(\frac{3}{4 \pi}\right)^{1 / 3} \rho_{\sigma}^{4 / 3}
$$

and $f\left(w_{\sigma}\right)$ is the spin kinetic-energy-density enhancement factor 


$$
f\left(w_{\sigma}\right)=\sum_{i=0}^{m} a_{i} w_{\sigma}^{i}
$$

where the variable $w_{\sigma}$ is a function of $t_{\sigma}$, and $t_{\sigma}$ is a function of the spin kinetic energy density $\tau_{\sigma}$ and spin density $\rho_{\sigma}$.

$$
\begin{aligned}
& w_{\sigma}=\left(t_{\sigma}-1\right) /\left(t_{\sigma}+1\right) \\
& t_{\sigma}=\tau_{\sigma}^{\mathrm{LSDA}} / \tau_{\sigma}
\end{aligned}
$$

where

$$
\tau_{\sigma}^{\mathrm{LSDA}} \equiv \frac{3}{10}\left(6 \pi^{2}\right)^{2 / 3} \rho_{\sigma}^{5 / 3}
$$

\section{IV.B. Meta-GGA correlation functional}

The M06-L correlation functional is based on the M05 correlation functional, again augmented by terms from Voorhis and Scuseria. The M05 correlation functional builds on work of Perdew and Wang, Stoll, Pavkidou, Preuss, and Becke. ${ }^{3,11,47,100}$ In the correlation functional, we treat the opposite-spin and parallel-spin correlation differently.

The opposite-spins correlation energy of our new functional is expressed as:

$$
E_{\mathrm{C}}^{\alpha \beta}=\int e_{\alpha \beta}^{\mathrm{UEG}}\left[g_{\alpha \beta}\left(x_{\alpha}, x_{\beta}\right)+h_{\alpha \beta}\left(x_{\alpha \beta}, z_{\alpha \beta}\right)\right] d r
$$

where $g_{\alpha \beta}\left(x_{\alpha}, x_{\beta}\right)$ is defined as:

$$
g_{\alpha \beta}\left(x_{\alpha}, x_{\beta}\right)=\sum_{i=0}^{n} c_{\mathrm{C} \alpha \beta, i}\left(\frac{\gamma_{\mathrm{C} \alpha \beta}\left(x_{\alpha}^{2}+x_{\beta}^{2}\right)}{1+\gamma_{\mathrm{C} \alpha \beta}\left(x_{\alpha}^{2}+x_{\beta}^{2}\right)}\right)^{i}
$$

and $h_{\alpha \beta}\left(x_{\alpha \beta}, z_{\alpha \beta}\right)$ is defined in eq. (5), with $x_{\alpha \beta}^{2} \equiv x_{\alpha}^{2}+x_{\beta}^{2}$ and $z_{\alpha \beta} \equiv z_{\alpha}+z_{\beta}$.

For parallel spins, 


$$
E_{\mathrm{C}}^{\sigma \sigma}=\int e_{\sigma \sigma}^{\mathrm{UEG}}\left[g_{\sigma \sigma}\left(x_{\sigma}\right)+h_{\sigma \sigma}\left(x_{\sigma}, z_{\sigma}\right)\right] D_{\sigma} d r
$$

where $g_{\sigma \sigma}\left(x_{\sigma}\right)$ is defined as:

$$
g_{\sigma \sigma}\left(x_{\sigma}\right)=\sum_{i=0}^{n} c_{\mathrm{C} \sigma \sigma, i}\left(\frac{\gamma_{\mathrm{C} \sigma \sigma} x_{\alpha}^{2}}{1+\gamma_{\mathrm{C} \sigma \sigma} x_{\alpha}^{2}}\right)^{i}
$$

and $h_{\sigma \sigma}\left(x_{\sigma}, z_{\sigma}\right)$ is defined in eq 5. $D_{\sigma}$ is the self-interaction correction factor

$$
D_{\sigma}=1-\frac{x_{\sigma}^{2}}{4\left(z_{\sigma}+C_{F}\right)}
$$

Significantly, $D_{\sigma}$ vanishes for any one-electron system.

Note that $e_{\alpha \beta}^{\mathrm{UEG}}$ and $e_{\sigma \sigma}^{\mathrm{UEG}}$ in eqs. (12) and (14) are the UEG correlation energy density for the anti-parallel-spin and parallel spin cases, and they can be extracted from the total UEG correlation energy density. ${ }^{100}$ The total correlation energy of the new correlation functional is given by

$$
E_{\mathrm{C}}=E_{\mathrm{C}}^{\alpha \beta}+E_{\mathrm{C}}^{\alpha \alpha}+E_{\mathrm{C}}^{\beta \beta}
$$

The values of the two non-linear parameters in eqs. (13) and (15) are taken from previous work. $^{17,44}$

$$
\gamma_{\mathrm{C} \alpha \beta}=0.0031, \quad \gamma_{\mathrm{C} \sigma \sigma}=0.06
$$

The values of the three non-linear parameters $\alpha_{\mathrm{X}}, \alpha_{\mathrm{C} \alpha \beta}$, and $\alpha_{\mathrm{C} \sigma \sigma}$ in eq. (5), as employed in eqs. (6), (12), and (14), are taken from a different previous work. ${ }^{12}$

\section{IV.C. Optimization of the new local meta-GGA}

All parameter optimizations were carried out in a self-consistent fashion. The parameters $a_{i}$ in eq $6, c_{\mathrm{C} \alpha \beta, i}$ in eq. (12), and $c_{\mathrm{C} \sigma \sigma, i}$ in eq. (14), along with the 
parameters $d_{\mathrm{i}}$ in $h_{\mathrm{X}}\left(x_{\sigma}, z_{\sigma}\right)$ (eq (6)), $d_{\mathrm{C} \alpha \beta, i}$ in $h_{\alpha \beta}\left(x_{\alpha \beta}, z_{\alpha \beta}\right)$ (eq (12)) and $d_{\mathrm{C} \sigma \sigma, i}$ in $h_{\sigma \sigma}\left(x_{\sigma}, z_{\sigma}\right)$ (eq. (14)) were determined by fitting to the data in the training set. To obtain the correct UEG limit, we enforce the following constraints:

$$
\begin{aligned}
& a_{0}+d_{0}=1 \\
& c_{\mathrm{C} \alpha \beta, i}+d_{\mathrm{C} \alpha \beta, i}=1 \\
& c_{\mathrm{C} \sigma \sigma, i}+d_{\mathrm{C} \sigma \sigma, i}=1
\end{aligned}
$$

We optimized the parameters in M06-L against accurate data to approximately minimize (see below for details) a training function $F$ defined by

$$
\begin{aligned}
& F=\operatorname{RMSEPB}(\mathrm{MGAE} 109)+\mathrm{RMSE}(\mathrm{IP} 13)+\mathrm{RMSE}(\mathrm{EA} 13)+ \\
& \mathrm{RMSE}(\mathrm{PA} 8)+\mathrm{RMSE}(\mathrm{BH} 76)+10 \times \mathrm{RMSE}(\mathrm{NCCE} 31)+ \\
& \mathrm{RMSE}(\mathrm{TMML} 30)+\mathrm{RMSE}(\mathrm{ABDE} 4)+ \\
& \mathrm{RMSE}(\mathrm{AE} 17)+\operatorname{RMSE}(\pi 13)
\end{aligned}
$$

where the terms have the following meaning: RMSEPB is the root-mean-squared error (RMSE) per bond for the MGAE109 database. The second term is the RMSE for the IP13 database. The third term is the RMSE for the EA13 database. RMSE(PA8) is the RMSE for the PA8 database of eight proton affinities. RMSE(BH76) is the RMSE for the 76 barrier heights in the HTBH38 and NHTBH38 databases. RMSE(NCCE31) is the RMSE for the 31 noncovalent complexation energies in the HB6/04, CT7/04, DI6/04, WI7/05, and PPS5/05 databases. RMSE(ABDE4) is the RMSE for the bond dissociation energies in the ABDE4/05 database. RMSE(TMML30) is the RMSE in the bond dissociation energies in the TMAE9/05 and MLBE21/05 databases. RMSE(AE17) is the RMSE for the 17 total atomic energies ${ }^{112}$ of the atoms from $\mathrm{H}$ to $\mathrm{Cl}$. $\operatorname{RMSE}(\pi 13)$ is the RMSE of the 13 energetic data in the $\pi \mathrm{IE} 3 / 06, \mathrm{PA}-\mathrm{CP} 5 / 06$, and PA-SB5/06 databases. 
We minimize the training function with respect to these parameters in a selfconsistent way by solving the Fock-Kohn-Sham equation using the basis sets and geometries described in Section III.A but subject to two constraints: $\left|c_{\mathrm{C} \alpha \beta, 0}\right|<5$ and $\left|c_{\mathrm{C} \sigma \sigma, 0}\right|<5$. Because of these constraints the training function is only approximately minimized, but the functional is more physical than for an unconstrained optimization. The M05 and M05-2X functionals were each parametrized against 35 data and have been tested on 354 data. Examination of eq. (22) shows that 314 data are used during the parametrization of M06-L.

All optimized parameters for M06-L are listed in Table 1. Notice that $a_{0}=$ 0.3987756 and $d_{0}=0.6012244$. One can interpret this as meaning that the new exchange functional has $40 \% \tau$-enhanced PBE exchange (similar to M05 exchange) and $60 \%$ modified VSXC exchange. One can also obtain small errors with a larger fraction of modified VSXC exchange, but we saw no reason to increase this fraction arbitrarily. We note that the VSXC functional was originally parametrized without enforcing the uniform-electron-gas limit in order to improve empirical performance, but the present functional does not require this compromise of an exact constraint.

\section{RESULTS AND DISCUSSION}

We compare the results obtained by the new M06-L functional to those for 11 other local functionals and 3 hybrid functionals. Note that in the present paper, we are focusing on the performance of the local functionals, and readers can find the performance of many other hybrid functionals in our previous work ${ }^{17,68,80,113}$ and the work of others. ${ }^{114-116}$ We include three hybrid functionals in the present work simply to 
provide perspective. We specifically omit high-Hartree-Fock exchange functionals like PWB6K, ${ }^{68} \mathrm{M} 05-2 \mathrm{X},{ }^{17}$ and $\mathrm{BMK}^{116}$ because they are well known to be inaccurate for many problems involving transition metals. Table 2 lists all 15 density functionals considered in this work. In each case we specify the year it was first published, the functional forms used for dependence on $\nabla \rho_{\sigma}$, whether or not the functional includes $\tau_{\sigma}$ in the exchange and correlation functional, and whether the correlation functional is selfcorrelation-free (SCorF). Table 2 also contains two columns (one for the exchange functional and one for the correlation functional) that tell whether or not the functional reduces to the correct uniform-electron-gas limit when $\nabla \rho_{\sigma} \rightarrow 0$ and $\tau_{\sigma} \rightarrow \tau_{\sigma}^{L S D A}$. In most of the comparisons we will gauge the quality of the results by mean unsigned errors (MUEs), which are the averages of the absolute deviations of calculated values from database reference values, and by mean signed errors (MSEs), which are used to detect systematic deviations. However, for atomization energies we use MUE per bond (MUEPB) and MSE per bond (MSEPB) because, as discussed in Section II, this allows ${ }^{105,113,117}$ more transferable comparison between databases with different average sizes of molecules. To make the trends more clear, in every table that ends with a mean error column we will list the methods in increasing order of the values in the key (overall) error column, which is always the last column of a given table.

Section II presented 22 energetic databases ( 1 in II.A, and 3, 1, 3, 6, 3, 1, 3, and 1 in II.B-II.H). Here we discuss them in the same order, but for discussion purposes we group them slightly differently (4 in V.A, and 4, 6, 3, 1, 3, and 1 in V. B-V.G), after which we provide some tests for bond lengths and vibrational frequencies. 


\section{V.A. Thermochemistry: AE, IP, EA, and PA results}

Table 3 summarizes the errors in atomization energies (AEs), ionization potentials (IPs), electron affinities (EAs), and proton affinities (PAs) for all tested functionals. Table 3 shows that the M05, VSXC, and M06-L methods give the best results for AE calculations.

OLYP, M06-L, and M06-Lhave the best performance for IP calculations, whereas BB95, mPWPW, and B3LYP give the best performance for EA calculations. For the calculation of proton affinities, B3LYP, PBE, and BP86 give the best performance

To compare their performance for thermochemistry, we defined the TMUE (total MUE) as the mean signed error over all 143 data in this table:

$$
\begin{aligned}
& \text { TMUE }=[\text { MUEPB }(\text { AE }) \times 109+\text { MUE }(I P) \times 13+\operatorname{MUE}(\text { EA }) \times 13+ \\
& \text { MUE }(\text { PA8) }] / 143
\end{aligned}
$$

If we use TMUE as a criterion of practical usefulness for main-group thermochemistry, Table 3 shows that M05 is the best functional, followed by VSXC and M06-L. The results in Table 3 confirm the point in Section IV that VSXC is the best local functional for main-group thermochemistry. It is encouraging that it is followed by the OLYP and M06-L functionals; all three match or outperform both the most popular hybrid functional, B3LYP, and its local version, BLYP, although they do not outperform M05. We next turn attention to 20 other databases to test for a local functional with good performance across the board.

\section{V.B. Thermochemical kinetics}

Table 4 gives the mean errors for the HTBH38/04 and NHTBH38/04 databases with the MG3S basis set. We also tabulated a value of mean MUE (called MMUE) that is 
defined as 1/4 times the MUE for heavy-atom transfer barrier heights plus 1/4 times the MUE for $\mathrm{S}_{\mathrm{N}} 2$ barrier heights plus 1/4 times the MUE for unimolecular and association barrier heights plus 1/4 times the MUE for hydrogen transfer barrier heights.

Table 4 shows that the M05, M06-L and VSXC methods give the best results for heavy-atom-transfer barrier height calculations. M05, OLYP and HCTH have the best performance for nucleophilic substitution barrier height calculations. M06-L, B3LYP, and $\mathrm{HCTH}$ give the best performance for unimolecular and association barrier height calculations. The M05, M06-L and B3LYP methods give the best performance for hydrogen transfer barrier height calculations, and they also give the lowest values of MMUE, which means they give the best overall performance for barrier height calculations.

Another quantity, average MUE or AMUE, is defined as:

$$
\operatorname{AMUE}=[\operatorname{MUE}(\Delta \mathrm{E}, 38)+\operatorname{MMUE}(\mathrm{BH} 76)] / 2
$$

where $\operatorname{MUE}(\Delta \mathrm{E}, 38)$ is the mean unsigned error in the energy of reactions for the 38 reactions in the $\mathrm{HTBH} 38$ and $\mathrm{NHTBH} 38$ database. If one prefers to use AMUE as a criterion to justify the performance of a DFT method for thermochemical kinetics, the conclusions one draws are essentially the same as above; in particular, the rank order of the eleven best functionals in Table 4 is the same using AMUE as using MMUE.

\section{V.C. Noncovalent interactions}

In general, noncovalent interactions are key elements determining many of the properties of soft materials. ${ }^{118-125}$ The mean errors for noncovalent interaction are listed in Tables 5 and 6. In Table 5, we use "no-cp" to denote calculations without the counterpoise correction for the BSSE, and we use "cp" to denote calculations that do 
include the counterpoise correction for the BSSE. In Table 5 and 6, we also defined a mean MUE:

$$
\operatorname{MMUE}=[\operatorname{MUE}(\text { no-cp })+\operatorname{MUE}(\mathrm{cp})] / 2
$$

This is a reasonable error criterion because the cp correction is sometimes an overestimate of BSSE, and because in practical work some calculations are carried out with cp corrections and some without. This is actually just a technical point in the present paper because the table shows that (because our basis set is large enough) the conclusions are the same if we base them on cp, no-cp or MMUE results.

Table 5 shows that PBE, M06-L, and M05 give the best performance for calculating the binding energies of the hydrogen bonding dimers in the HB6/04 database. These three methods also give the best performance for calculating the binding energies of the dipole interaction complexes in the DI6/04 database.

Charge transfer complexes have long been recognized as a difficulty for local functionals, ${ }^{126,127}$ Table 5 confirms that most local functionals give very poor performance for calculating the binding energies for the complexes in the CT7/04 databases. M06-L, while not as accurate for this property as the hybrid M05 and B3LYP functional, is the sixth best performing local functional in Table 5, and its MUE of 1.61 $\mathrm{kcal} / \mathrm{mol}$ is the same as the average $(1.61 \mathrm{kcal} / \mathrm{mol}$ as given in the last row $)$ over all 15 functionals in the table.

We note that weak interactions and $\pi-\pi$ stacking interactions play a dominant role in stabilizing various biopolymers, for example, the double helix structure of DNA, ${ }^{128,129}$ and such interactions are also important for protein folding ${ }^{130}$ and supramolecular design. ${ }^{131,132}$ Table 5 shows that the quality of M06-L for describing $\pi-\pi$ stacking 
interactions is much better than all other local functionals and is also better than M05, B3LYP, and TPSSh. The best functional for noncovalent interactions is M05-2X, ${ }^{17}$ which is not included in the present study because it is not designed to be a universal functional for treating transition metals as well as main-group chemistry.

The overall performance for noncovalent interactions can be judged by the mean MMUE, which is defined as:

$$
\begin{aligned}
\text { MMMUE } & =[\operatorname{MMUE}(\mathrm{HB})+\operatorname{MMUE}(\mathrm{CT})+\operatorname{MMUE}(\mathrm{DI}) \\
& +\operatorname{MMUE}(\mathrm{WI})+\operatorname{MMUE}(\mathrm{PPS})] / 5
\end{aligned}
$$

Notice that the five components in eq. (26) place different requirements on a density functional. For example, high accuracy for charge transfer complexes is not well correlated with high accuracy for weak interactions. If we use MMMUE as a criterion to evaluate the overall performance of DFT methods for noncovalent interactions, we can see from Table 5 that M05, M06-L, and TPSSh are the best functionals in the present study.

We have recently tested 40 functionals against the S22 database, and we found that the six most accurate functionals were all hybrid functionals. ${ }^{108}$ Therefore this is a difficult test for local functionals. Table 6 presents results for the S22 database. Note that S22 is a large, diverse database that is not in the training set of the M06-L functional. It is encouraging that M06-L performs well for this database of biologically important interactions. In fact it is more than a factor of two better than any other local functional, and it is also considerably more accurate than the three hybrid functionals in Table 6 . The S22 database was not used in the training step.

\section{V.D. Transition element bond energies}


Metal-metal and metal-ligand bonding is very important in many application areas. ${ }^{52,60,133-146}$ Table 7 summarizes the results for the TMAE9/05, MLBE21/05, and $3 d$ TMRE18/06 databases. For the TMAE9/05 database of bond energies of transition metal dimers, G96LYP, BLYP, and M06-L give the best results. For the MLBE21/05 database of metal-ligand compounds, TPSSh, M05, and M06-L give the best performance, and M06-L, M05, and HCTH perform best for the $3 d$ TMRE18/06 database. Thus M06-L is the only functional in the top three for all these databases.

In Table 7, MMUE is the average of the MUE for the TMAE9/05, MLBE21/05, and $3 d$ TMRE18/06 databases, and M06-L, M05, and G96LYP give the smallest MMUE. The good performance of M06-L on all three databases is encouraging, especially since 3dTMAE18/06 was not used during parametrization.

\section{V.E. Trends in alkyl bond dissociation energies}

Table 8 summarizes the results for the trends in $\mathrm{R}-\mathrm{X}$ BDEs $(\mathrm{R}=\mathrm{Me}$ and $i-\mathrm{Pr} ; \mathrm{X}=$ $\mathrm{CH}_{3}$ and $\mathrm{OCH}_{3}$ ). Table 7 shows that BB95, PBE, and M05 gives the best performance for this $\mathrm{BDE}$ database. The $\mathrm{ABDE}$ database was originally created in response to previous criticism $^{75,147}$ of DFT that it performs more poorly for larger alkyl groups than for methyl. It is encouraging that the accuracy of M06-L degrades less rapidly than other functionals as the alkyl group size is increased from methyl to isopropyl.

\section{V.F. Tests for $\pi$ systems}

Table 9 summarizes the results for the energetic data in the $\pi \mathrm{IE} 3 / 06, \mathrm{PA}-\mathrm{CP} 5 / 06$, and PA-SB5/06 databases. M05, PBE, and B3LYP give the best performance. M06-L performs strikingly well (on a relative basis as compared to other local functionals and to B3LYP and TPSSh) for isomerization energies of conjugated systems, but less accurate 
for proton affinities of $\pi$ conjugated systems. The former problem provides a difficult test for most DFT methods, ${ }^{69,77}$ and the latter problem is related to the notorious problem of overestimation of polarizabilities and hyperpolarizabilities of conjugated systems by DFT. ${ }^{148,149}$ It seems to be very hard to treat the latter problem with local functionals.

\section{V.G. Metal atom excitation energy}

Table 10 presents the performance for the MAEE5 database of atomic excitation energies. Among the tested DFT methods, VSXC, M06-L, and OLYP give the best performance, whereas BB95 gives poor results for this database. In fact the considerable improvement for this data set of M06-L over that obtained with M05 is a significant point in convincing us that the functional form has been improved, especially since no excitation energies were used in training.

\section{V.H. Overall performance for energetic data}

Table 11 is a summary of the performance of the tested methods for all quantities studied in this paper. To construct Table 11, we first ported the final columns of Tables 310. Then we computed the combined MUE (CMUE) column as a straight average of these eight mean unsigned errors. The average of all these averages is $5.72 \mathrm{kcal} / \mathrm{mol}$, but the average of the eight columns range from 1.5 to $9.1 \mathrm{kcal} / \mathrm{mol}$. Thus some columns of Table 11 have a larger effect on CMUE than others. This is unavoidable and there can be no universally satisfactory way to combine errors for different kinds of properties. Nevertheless we do tabulate one more figure of merit, called the weighted MUE. For this column we scaled each of the first eight numerical columns of Table 11 by $(5.72$ $\mathrm{kcal} / \mathrm{mol}$ )/Average, where Average is the average for that column (as given in the last row). Thus, for example, every value in the Main-Group Thermochemistry column is 
scaled by $5.72 / 1.85$. The WMUE is the average of the scaled values. Encouragingly, the conclusions drawn from the CMUE and WMUE columns are similar. (One could try other, more sophisticated weightings, but our goal is to understand the trends, not to develop arbitrary statistics.)

The M06-L weighted mean unsigned error is better than that of all of the hybrid functionals tested, whereas none of the other local functional is better than any of them.

\section{V.I. Bond lengths and frequencies}

Table 12 is a summary of the performance of the M06-L functional, as well as that of B3LYP, TPSS, BLYP, PBE, and VSXC, for the prediction of the bond lengths of 13 main-group molecules in the MGBL19 database and 13 metal-ligand bonds in the MLBL13/05 database. For the main-group database, Table 12 shows that M06-L and VSXC give the smallest MUE for the prediction of bond lengths of main-group compounds; both outperform the B3LYP functional, and BLYP, PBE, and TPSS all give considerably worse geometries for the main-group database. In contrast, VSXC performs worst for the metal-ligand database, and the best performing functionals for this database are PBE, TPSS, and B3LYP. We also tabulated a quantity called AMUE in Table 12; this is an average of the errors over the two bond-length databases. Encouragingly, M06-L gives the smallest AMUE.

Table 13 presents the results for the prediction of harmonic frequencies. Overall the best performer is VSXC, followed by B3LYP and M06-L. M06-L has a mean unsigned error of $45 \mathrm{~cm}^{-1}$ for frequencies greater than $2000 \mathrm{~cm}^{-1}$ and a mean unsigned error of $33 \mathrm{~cm}^{-1}$ for those under $2000 \mathrm{~cm}^{-1}$. 
We note that no geometries or frequencies were used in the parametrization of M06-L.

\section{V.J. Comparison to a fifth-rung semiempirical functional}

Recently, Grimme ${ }^{150}$ proposed a fifth-rung semiempirical functional, called B2PLYP, which employs the Kohn-Sham orbitals and eigenvalues as input for a standard MP2 perturbation correction (earlier fifth-rung functionals, that is, functionals that depend on the virtual orbitals, are discussed elsewhere $\left.{ }^{67,117,151-153}\right)$. The two new semiempirical parameters in B2-PLYP were optimized against the G2/97 ${ }^{154}$ neutral test set. (Note that, also discussed by Perdew et al., ${ }^{20}$ there five other empirical parameters in the B2-PLYP functional: one is in the Becke $88^{7}$ exchange and four in the LYP correlation. ${ }^{8}$ ) Although B2-PLYP has less parameters than M06-L, it involves HF exchange, and it scales as $N^{5}$ (where $N$ is the size of a system). We were asked by a referee to examine the performance of B2-PLYP in the context of the present work. We are happy to do so, but rather than add B2-PLYP to all tables, we will examine it for two representative databases ${ }^{155}$ of main group thermochemistry and thermochemical kinetics, for the prototype problem of $\pi-\pi$ stacking in benzene dimer, and for a problem recently singled out ${ }^{156}$ by Grimme. The representative databases are AE6 for atomization energies and BH6 for barrier heights. The data in each of these databases are subsets of the data in MGAE109 and BH76; in particular they have been shown to be subsets for which performance is indicative of performance on the larger data bases. ${ }^{80,155}$

The problem recently studied by Grimme and suggested by him to be "a mandatory benchmark for new density functionals" is the isomerization energy of tetramethylbutane to $n$-octane. Grimme found that the accurate result is $+1.9 \mathrm{kcal} / \mathrm{mol}$; 
three ab initio wave function calculations gave $-11.5,+1.4$, and $+4.6 \mathrm{kcal} / \mathrm{mol}$, B2-PLYP gave $-3.5 \mathrm{kcal} / \mathrm{mol}$, and seven density functionals gave values in the range -9.9 to -5.5 $\mathrm{kcal} / \mathrm{mol}$. We find here that M06-L gives $+0.6 \mathrm{kcal} / \mathrm{mol}$. Grimme concluded that the density functional results in his paper are "bad news for standard Kohn-Sham DFT as it seems difficult to obtain the necessary information about electron pairs and their interactions from simple considerations of the electron density alone. Of course we are not questioning the exactness and usefulness of the Hohenberg-Kohn theorems or the Kohn-Sham approach in general, but just the human ability to find accurate density functionals in practice. The better results with the new virtual orbital-dependent B2PLYP functional that includes in part the necessary terms shows, however, the way to go in the future." We are not questioning the usefulness of fifth rung functionals when expensive calculations are affordable, but it is encouraging that the less expensive M06-L calculations outperform B2-PLYP for this important benchmark. We note that Grimme's paper was published after our paper was submitted.

Table 14 compares errors for the thermochemical AE $6^{155}$ database of six atomization energies, for the kinetics $\mathrm{BH} 6^{155}$ database of six barrier heights, for the binding energy ${ }^{157}$ of parallel-displaced benzene dimer, and for the isomerization energy ${ }^{156,158}$ of octane. From Table 4, one can see that B2-PLYP significantly outperforms M06-L for barrier heights, which is not surprising because B2-PLYP contains $47 \% \mathrm{HF}$ exchange, whereas M06-L is a local functional without any HF exchange. Furthermore the comparisons already presented show that barrier heights are the one area where M06-L is significantly outperformed by new-generation density functionals like M05 $5^{17,44}$ and M05-2X $\mathrm{X}^{17}$ (although not by popular functionals like 
B3LYP). Turning to the other tests in Table 14, we see that the expensive B2-PLYP outperforms M06-L by $11 \%$ for thermochemistry, as shown by the MUE for the AE6 database, but it is not as accurate for the binding energy of benzene dimer and the isomerization energy of octane in Table 14, which are both notorious examples for which many density functionals fail. ${ }^{70,156}$ Furthermore, Table 14 shows that B2-PLYP is one order of magnitude more expensive than M06-L as measured by the computer time for a benzene dimer calculation, and as one increases system size, this ratio of computer times will become more dramatic because M06-L scales as $N^{3}$ whereas B2-PLYP scales as $N^{5}$. Note that the calculations in Ref. 156 employed a polarized quadruple zeta basis for B2PLYP, which requires larger basis sets than M06-L; nevertheless the timing in Table 14 is for the MG3S polarized triple zeta basis set (using a polarized quadruple zeta basis set would make the timing comparison less favorable for B2-PLYP).

\section{CONCLUDING REMARKS}

This paper presents a new local meta-GGA exchange-correlation functional, M06L, for thermochemistry, thermochemical kinetics, and noncovalent interactions. This functional builds on earlier work of several authors, ${ }^{6,11,12,15,17,44,49,100-103}$ and it is designed to incorporate spin kinetic energy density in a balanced way in the exchange and correlation functionals. In addition, it satisfies the uniform-electron-gas limit, and it is self-correlation-free. The M06-L functional was comparatively assessed against 22 diverse energetic databases, a bond length test set, and a set of 36 harmonic vibrational frequencies.

The assessments include main group chemistry, transition metal chemistry, and biological chemistry. From these assessments and from comparison to results for 14 
functionals in the literature, we draw the conclusion, based on an analysis of mean unsigned errors, that the M06-L functional gives the best overall performance of any functional for a combination of thermochemistry, thermochemical kinetics, metallochemical and noncovalent interactions, bond lengths, and vibrational frequencies. It is striking that it outperforms the second best local functional by almost a factor of two, even though the uniform-electron-gas limit was sacrificed in that functional to improve empirical performance. Furthermore Tables 3-13 show that M06-L does well by being the best or reasonably close to the best local functional in almost all categories, the main (and troubling) exceptions being proton affinities of conjugated $\pi$ bonded systems and electron affinities. We especially recommend the M06-L functional for the study of systems involving transition metal bonding since the performance is better than that of all other functionals except M05 by a large margin (It outperforms M05 by only 19\%.).

The new M06-L functional not only excels in comparison to other local functionals, its average overall performance for energetic quantities (as measured by overall performance on both of the last two columns of Table 11) is better than any of the three hybrid functionals we tested, including the best previous broadly accurate functional (M05) and the very popular B3LYP one. Since the B3LYP functional has become a generally accepted standard for a broadly accurate functional, it is useful to mention that the mean unsigned error for the local M06-L functional is smaller than that for the hybrid B3LYP functional by a factor of 1.5 if measured by either of the last two columns of Table 11.

From a fundamental point of view, as pointed by Becke ${ }^{103}$ in a related context, it is important to carry out studies like the present one to learn the limit of accuracy of 
particular kinds of density functionals, in his case hybrid GGAs, and in our case metaGGAs without Hartree-Fock exchange. As compared to the earlier tests of Becke and many others that focused exclusively on main group thermochemistry of small molecules, this study includes barriers, noncovalent interactions, transition metals, and larger systems. Our conclusions overturn the widespread belief that local functionals are not capable of improving on the broad average accuracy of the best current hybrid functionals.

It is very encouraging that we succeeded in developing a local density functional with very broad applicability. From a practical point of view, the new high-performance local functional presented here, because of the computational efficiencies possible with local functionals, should be immediately useful for a myriad of applications involving complex systems, such as organometallic and inorganometallic chemistry, biological problems, soft materials, and molecular solids (including ice). We especially stress its usefulness for condensed-phase systems and molecular recognition problems (including supramolecular chemistry and protein assemblies) when noncovalent interactions are very important and hybrid functionals are prohibitively expensive.

ACKNOWLEDGMENTS. The authors are grateful to Nathan Schultz for helpful discussions. This work was supported in part by the U. S. Department of Energy, Office of Basic Energy Sciences under grant number DE-FG02-86ER13579 (kinetics), by the National Science Foundation under grant numbers CHE03-49122 (complex systems) and ITR04-28774 (planetary ice), and by the Office of Naval Research under award number N00014-05-0538 (tools and software). 


\section{References}

W. Kohn and L. J. Sham, Phys. Rev. 140, 1133 (1965).

S. H. Vosko, L. Wilk, and M. Nusair, Can. J. Phys . 58, 1200 (1980).

J. P. Perdew and Y. Wang, Phys. Rev. B 45, 13244 (1992).

D. C. Langreth and M. J. Mehl, Phys. Rev. B 28, 1809 (1983).

J. P. Perdew, Phys. Rev. B 33, 8822 (1986).

A. D. Becke, J. Chem. Phys. 84, 4524 (1986).

A. D. Becke, Phys. Rev. A 38, 3098 (1988).

C. Lee, W. Yang, and R. G. Parr, Phys. Rev. B 37, 785 (1988).

T. Ziegler, Chem. Rev. 91, 651 (1991).

M. Filatov and W. Thiel, Mol. Phys., 847 (1997).

A. D. Becke, J. Chem. Phys. 104, 1040 (1996).

T. V. Voorhis and G. E. Scuseria, J. Chem. Phys. 109, 400 (1998).

J. Tao, J. P. Perdew, V. N. Staroverov, and G. E. Scuseria, Phys. Rev. Lett. 91, $146401(2003)$.

A. D. Becke, J. Chem. Phys. 98, 5648 (1993).

J. P. Perdew, M. Ernzerhof, and K. Burke, J. Chem. Phys. 105, 9982 (1996).

C. Adamo and V. Barone, J. Chem. Phys. 108, 664 (1998).

Y. Zhao, N. E. Schultz, and D. G. Truhlar, J. Chem. Theory Comput. 2, 364 (2006).

P. Hohenberg and W. Kohn, Phys. Rev. 136, 864 (1964).

J. P. Perdew and A. Zunger, Phys. Rev. B 23, 5048 (1981). 
J. P. Perdew, A. Ruzsinszky, J. Tao, V. N. Staroverov, G. E. Scuseria, and G. I. Csonka, J. Chem. Phys. 123, 62201 (2005).
E. J. Baerends, D. E. Ellis, and P. Ros, Chem. Phys. 2, 41 (1973).

B. I. Dunlap, J. W. D. Connolly, and J. R. Sabin, J. Chem. Phys. 71, 3396 (1979).

O. Vahtras, J. Almlöf, and M. W. Feyereisen, Chem. Phys. Lett. 213, 514 (1993).

R. A. Kendall, E. Apra, D. E. Bernholdt, E. J. Bylaska, M. Dupuis, G. I. Fann, R. J. Harrison, J. Ju, J. A. Nichols, J. Nieplocha, T. P. Straatsma, T. L. Windus, and A. T. Wong, Comput. Phys. Commun. 128, 260 (2000).

5 G. Te Velde, F. M. Bickelhaupt, E. J. Baerends, C. Fonseca Guerra, S. J. A. Van Gisbergen, J. G. Snijders, and T. Ziegler, J. Comp. Chem. 22, 931 (2001).

J. VandeVondele, M. Krack, F. Mohamed, M. Parrinello, T. Chassaing, and J. Hutter, Comput. Phys. Commun. 167, 103 (2005).

27 Y. Jung, A. Sodt, P. M. W. Gill, and M. Head-Gordon, Proc. Natl. Acad. Sci. USA 102, 6692 (2005).

28 K. Eichkorn, O. Treutler, H. Oehm, M. Haeser, and R. Ahlrichs, Chem. Phys. Lett. 240, 283 (1995).

K. Eichkorn, F. Weigend, O. Treutler, and R. Ahlrichs, Theo. Chem. Acc. 97, 119 (1997).

L. Füsti-Molnár and P. Pulay, Theochem 666-667, 25 (2003). Y.-B. Wang and Z. Lin, J. Am. Chem. Soc. 25, 6072 (2003). M. J. Frisch, G. W. Trucks, H. B. Schlegel, G. E. Scuseria, M. A. Robb, J. R. Cheeseman, J. A. Montgomery, T. V. Jr., K. N. Kudin, J. C. Burant, J. M. Millam, S. S. Iyengar, J. Tomasi, V. Barone, B. Mennucci, M. Cossi, G. Scalmani, N. 
Rega, G. A. Petersson, H. Nakatsuji, M. Hada, M. Ehara, K. Toyota, R. Fukuda, J. Hasegawa, M. Ishida, T. Nakajima, Y. Honda, O. Kitao, H. Nakai, M. Klene, X. Li, J. E. Knox, H. P. Hratchian, J. B. Cross, C. Adamo, J. Jaramillo, R. Gomperts, R. E. Stratmann, O. Yazyev, A. J. Austin, R. Cammi, C. Pomelli, J. W. Ochterski, P. Y. Ayala, K. Morokuma, G. A. Voth, P. Salvador, J. J. Dannenberg, G. Zakrzewski, S. Dapprich, A. D. Daniels, M. C. Strain, O. Farkas, D. K. Malick, A. D. Rabuck, K. Raghavachari, J. B. Foresman, J. V. Ortiz, Q. Cui, A. G. Baboul, S. Clifford, J. Cioslowski, B. B. Stefanov, G. Liu, A. Liashenko, P. Piskorz, I. Komaromi, R. L. Martin, D. J. Fox, T. Keith, M. A. Al-Laham, C. Y. Peng, A. Nanayakkara, M. Challacombe, P. M. W. Gill, B. Johnson, W. Chen, M. W. Wong, C. Gonzalez, and J. A. Pople, Gaussian03 (Gaussian, Inc., Pittsburgh PA, 2003).

G. E. Scuseria and V. N. Staroverov, in Theory and Application of Computational Chemistry: The First 40 Years, edited by C. E. Dykstra, G. Frenking, K. S. Kim, and G. E. Scuseria (Elsevier, Amsterdam, 2005), p. 669. J. Heyd and G. E. Scuseria, J. Chem. Phys. 120, 7274 (2004). J. Heyd and G. E. Scuseria, J. Chem. Phys. 121, 1187 (2004).

J. Heyd, J. E. Peralta, G. E. Scuseria, and R. L. Martin, J. Chem. Phys. 123, $174101(2005)$.

J. Paier, M. Marsman, K. Hummer, G. Kresse, I. C. Gerber, and J. G. Ángyán, J. Chem. Phys. 124, 154709 (2006). N. Schultz, Y. Zhao, and D. G. Truhlar, J. Phys. Chem. A 109, 4388 (2005). N. Schultz, Y. Zhao, and D. G. Truhlar, J. Phys. Chem. A 109, 11127 (2005). 
O. V. Gritsenko, P. R. T. Schipper, and E. J. Baerends, J. Chem. Phys. 107, 5007 (1997).

N. C. Handy and A. J. Cohen, Mol. Phys. 99, 403 (2001).

A. D. Becke, J. Chem. Phys. 119, 2972 (2003).

A. D. Becke, J. Chem. Phys. 122, 64101 (2005).

Y. Zhao, N. E. Schultz, and D. G. Truhlar, J. Chem. Phys. 123, 161103 (2005)

Note that in this communication we interchanged $\mathrm{c}_{\mathrm{C} \alpha \beta, \mathrm{i}}$ and $\mathrm{c}_{\mathrm{C} \sigma \sigma, \mathrm{i}}$ in Table 1. In addition, "reduced density $x_{\sigma}$ " before eq. (1) should read "reduced density gradient $x_{\sigma}{ }^{\prime \prime}$.

P. M. W. Gill, Mol. Phys. 89, 433 (1996).

J. P. Perdew, K. Burke, and M. Ernzerhof, Phys. Rev. Lett 77, 3865 (1996).

J. P. Perdew, in Electronic Structure of Solids '91, edited by P. Ziesche and H. Eschig (Akademie Verlag, Berlin, 1991), p. 11.

F. A. Hamprecht, A. J. Cohen, D. J. Tozer, and N. C. Handy, J. Chem. Phys. 109, $6264(1998)$.

A. D. Boese and N. C. Handy, J. Chem. Phys. 116, 9559 (2002).

P. J. Stephens, F. J. Devlin, C. F. Chabalowski, and M. J. Frisch, J. Phys. Chem. 98, 11623 (1994).

V. N. Staroverov, G. E. Scuseria, J. Tao, and J. P. Perdew, J. Chem. Phys. 119, 12129 (2003).

T. Lovelll, R. Stranger, and J. E. McGrady, Inorg. Chem. 40, 39 (2001).

M. Reiher, O. Salomon, and B. A. Hess, Theo. Chem. Acc. 107, 48 (2001).

J. N. Harvey, R. Poli, and K. M. Smith, Coord. Chem. Rev. 238-239, 347 (2003). 
J.-L. Carreón-Macedo and J. N. Harvey, J. Am. Chem. Soc. 126, 5789 (2004).

R. Poli, J. Organomet. Chem. 689, 4291 (2004).

C. Hermann, J. Nevgebauer, J. A. Gladysz, and M. Reiher, Inorg. Chem. 44, 6175 (2005).

D. M. Jenkins and J. C. Peters, J. Am. Chem. Soc. 127, 7148 (2005).

F. Neese, J. Inorg. Biochem. 100, 716 (2006).

J.-L. Carreón-Macedo and J. N. Harvey, Phys. Chem. Chem. Phys. 8, 93 (2006).

M. P. Mehn, S. D. Brown, T. K. Paine, W. W. Brennessel, C. J. Cramer, J. C.

Peters, and L. J. Que, Dalton Trans. 2006, 1347 (2006).

I. Rudra, Q. Wu, and T. V. Voorhis, J. Chem. Phys. 124, 24103 (2006).

M. C. Holthausen, J. Comp. Chem. 26, 1505 (2005).

R. L. Martin and P. J. Hay, J. Chem. Phys. 75, 4539 (1981).

B. J. Lynch, Y. Zhao, and D. G. Truhlar, J. Phys. Chem. A 107, 1384 (2003).

B. J. Lynch and D. G. Truhlar, J. Phys. Chem. A 107, 3898 (2003).

Y. Zhao, B. J. Lynch, and D. G. Truhlar, Phys. Chem. Chem. Phys. 7, 43 (2005).

Y. Zhao and D. G. Truhlar, J. Phys. Chem. A 109, 5656 (2005).

Y. Zhao and D. G. Truhlar, J. Phys. Chem. A 110, 10478 (2006).

Y. Zhao, N. González-García, and D. G. Truhlar, J. Phys. Chem. A 109, 2012 (2005) (E) 2006, 110, 4942.

Y. Zhao and D. G. Truhlar, J. Chem. Theory Comput. 1, 415 (2005).

P. Jurecka, J. Sponer, J. Cerny, and P. Hobza, Phys. Chem. Chem. Phys. 8, 1985 (2006).

Y. Zhao and D. G. Truhlar, J. Chem. Phys. 124, 224105 (2006). 
F. Furche and J. P. Perdew, J. Chem. Phys. 124, 044103 (2006).

E. I. Izgorodina, M. L. Coote, and L. Radom, J. Phys. Chem. A 109, 7558 (2005).

A. P. Scott and L. Radom, J. Phys. Chem. 100, 16502 (1996).

H. L. Woodcock, H. F. Schaefer, and P. R. Schreiner, J. Phys. Chem. A 106, 11923 (2002).

See EPAPS Document No. for all previously published databases.

This document can be reached through a direct link in the online article's HTML reference section or via the EPAPS homepage

(http://www.aip.org/pubservs/epaps.html).

P. L. Fast, J. Corchado, M. L. Sanchez, and D. G. Truhlar, J. Phys. Chem. A 103, 3139 (1999).

Y. Zhao and D. G. Truhlar, J. Phys. Chem. A 108, 6908 (2004).

J. M. L. Martin, J. El-Yazal, and J.-P. Francois, Mol. Phys. 86, 1437 (1995).

J. M. L. Martin, J. Chem. Phys. 100, 8186 (1994).

J. A. Pople, M. Head-Gordon, and K. Raghavachari, J. Chem. Phys. 87, 5968 (1987).

P. L. Fast, M. L. Sanchez, and D. G. Truhlar, Chem. Phys. Lett. 306, 407 (1999).

L. A. Curtiss, P. C. Redfern, K. Raghavachari, V. Rassolov, and J. A. Pople, J. Chem. Phys. 110, 4703 (1999).

L. A. Curtiss, K. Raghavachari, P. C. Redfern, V. Rassolov, and J. A. Pople, J. Chem. Phys. 109, 7764 (1998).

M. J. Frisch, J. A. Pople, and J. S. Binkley, J. Chem. Phys. 80, 3265 (1984). 
W. J. Hehre, L. Radom, P. v. R. Schleyer, and J. A. Pople, Ab Initio Molecular Orbital Theory, 1st ed. (Wiley, New York, 1986).

P. L. Fast and D. G. Truhlar, J. Phys. Chem. A 104, 6111 (2000).

M. O. Sinnokrot and C. D. Sherrill, J. Phys. Chem. A 108, 10200 (2004).

F. Weigend, F. Furche, and R. Ahlrichs, J. Chem. Phys. 119, 12753 (2003).

D. E. Woon and J. T.H. Dunning, J. Chem. Phys. 98, 1358 (1993).

N. B. Balabanov and K. A. Peterson, J. Chem. Phys. 123, 064107 (2005).

M. M. Quintal, A. Karton, M. A. Iron, A. D. Boese, and J. M. L. Martin, J. Phys. Chem. A 110, 709 (2006).

W. J. Stevens, M. Krauss, H. Basch, and P. G. Jasien, Can. J. of Chem. 70, 612 (1992).

D. Andrae, U. Haeussermann, M. Dolg, H. Stoll, and H. Preuss, Theor. Chim. Acta 77, 123 (1990).

K. Raghavachari and G. W. Trucks, J. Chem. Phys. 91, 1062 (1989).

S. F. Boys and F. Bernardi, Mol. Phys. 19, 553 (1970).

D. W. Schwenke and D. G. Truhlar, J. Chem. Phys. 82, 2418 (1985) 1987, 86, $3760(\mathrm{E})$.

H. Stoll, C. M. E. Pavkidou, and H. Preuss, Theor. Chim. Acta 49, 143 (1978).

A. D. Becke, J. Chem. Phys. 109, 2092 (1998).

A. D. Becke, J. Chem. Phys. 112, 4020 (2000).

A. D. Becke, J. Chem. Phys. 107, 8554 (1997).

A. D. Rabuck and G. E. Scuseria, Chem. Phys. Lett. 309, 450 (1999). 
Y. Zhao, J. Pu, B. J. Lynch, and D. G. Truhlar, Phys. Chem. Chem. Phys. 6, 673 (2004).

106

E. R. Johnson, R. A. Wolkow, and G. A. DiLabio, Chem. Phys. Lett. 394, 334 (2004).

107

108

109

110

111

112

114
J. C. Sancho-Garcia and J. Cornil, J. Chem. Phys. 121, 3096 (2004).

Y. Zhao and D. G. Truhlar, J. Chem. Theory Comput., submitted (2006).

G. C. L. Chan, D. J. Tozer, and N. C. Handy, J. Chem. Phys. 107, 1 (1997).

T. V. Voorhis and G. E. Scuseria, Mol. Phys. 92, 601 (1997).

J. W. Negele and D. Vautherin, Phys. Rev. C. 5, 1472 (1972).

S. J. Chakravorty, S. R. Gwaltney, E. R. Davidson, F. A. Parpia, and C. F. F. Fischer, Phys. Rev. A 47, 3649 (1993).

Y. Zhao, B. J. Lynch, and D. G. Truhlar, J. Phys. Chem. A 108, 2715 (2004).

P. J. Wilson, T. J. Bradley, and D. J. Tozer, J. Chem. Phys. 115, 9233 (2001).

X. Xu and W. A. Goddard, Proc. Natl. Acad. Sci. USA 101, 2673 (2004).

A. D. Boese and J. M. L. Martin, J. Chem. Phys. 121, 3405 (2004).

Y. Zhao, B. J. Lynch, and D. G. Truhlar, J. Phys. Chem. A 108, 4786 (2004).

I. W. Hamley, Angew. Chemie Int. Ed. 42, 1692 (2003).

G. K. Ghosh, Bull. Mat. Sci. 26, 3 (2003).

T. Kato, N. Misoshita, and K. Kishimoto, Angew. Chemie Int. Ed. 45, 38 (2005).

J. Wu, AIChE J. 52, 1169 (2006).

M. Lehmann, C. Köhn, H. Meier, S. Renker, and A. Oehlhof, J. Mat. Chem. 16, 441 (2006).

R. Holyst, Soft Matter 1, 329 (2005). 
A. Casey, G. F. Fassell, M. McNamara, H. J. Byrne, and G. Chambers, Synthetic Metals 153, 357 (2005).

M. R. Wilson, Int. Rev. Phys. Chem. 24, 421 (2005).

E. Ruiz, D. R. Salahub, and A. Vela, J. Am. Chem. Soc. 117, 1141 (1995).

E. Ruiz, D. R. Salahub, and A. Vela, J. Phys. Chem. 100, 12265 (1996).

E. T. Kool, J. C. Morales, and K. M. Guckian, Angew. Chemie Int. Ed. 39, 990 (2000).

P. Barthelemy, S. J. Lee, and M. Grinstaff, Pure Appl. Chem. 77, 2133 (2005).

J. Vondrásek, L. Bendová, V. Klusák, and P. Hobza, J. Am. Chem. Soc. 127, 2615 (2005).

H. Mansikkamaeki, M. Nissinen, and K. Rissanen, Angew. Chemie Int. Ed. 43, 1243 (2004).

M. Vázquez, M. R. Bermejo, M. Licchelli, A. M. González-Noya, R. M. Pedrido, C. Sangregorio, L. Sorace, A. M. García-Deibe, and J. Sanmartín, Eur. J. Inorg. Chem. 17, 3479 (2005).

J. Hautman and M. L. Klein, NATO ASI Ser. E 205, 395 (1991).

K. D. Karlin, Science 261, 701 (1993).

R. H. Crabtree, The Organometallic Chemistry of the Transition Metals, 2nd ed. (Wiley, New York, 1994).

S. M. George, Chem. Rev. 95, 475 (1995).

G. A. Somorjai, Chem. Rev. 96, 1223 (1995).

M. A. Ratner, B. Davis, M. Kemp, V. Mujica, A. Roitberg, and S. Yaliraki, Ann. N. Y. Acad. Sci. 852, 22 (1998). 
Transition State Modeling for Catalysis, edited by D. G. Truhlar and K.

Morokuma (American Chemical Sociaty, Washington, DC, 1999).

140

E. R. Davidson, Chem. Rev. 100, 351 (2000).

P. E. M. Siegbahn and M. R. A. Blomberg, Chem. Rev. 100, 421 (2000).

J. A. Gladysz, Chem. Rev. 100, 1167 (2000).

Handbook on Metalloproteins, edited by I. Bertini, A. Sigel, and H. Sigel

(Dekker, New York, 2001).

A. K. Rappe, W. M. Skiff, and C. J. Casewit, Chem. Rev. 100, 1435 (2000).

C. Coperat, M. Chabonas, R. P. Saint-Arromon, and J.-M. Basset, Angew.

Chemie Int. Ed. 42, 156 (2003).

G. Cavigliasso and R. Stranger, Inorg. Chem. 44, 5081 (2005).

L. A. Curtiss, K. Raghavachari, P. C. Redfern, and J. A. Pople, J. Chem. Phys. 112, $7374(2000)$.

B. Champagne, E. A. Perpete, S. J. A. van Gisbergen, E.-J. Baerends, J. G.

Snijders, C. Soubra-Ghaoui, K. A. Robins, and B. Kirtman, J. Chem. Phys. 109, 10489 (1998).

B. Champagne, E. A. Perpete, D. Jacquemin, S. J. A. V. Gisbergen, E.-J.

Baerends, C. Soubra-Ghaoui, K. A. Robins, and B. Kirtman, J. Phys. Chem. A 104, 4755 (2000).

S. Grimme, J. Chem. Phys. 124, 034108 (2006).

I. Grabowski, S. Hirata, S. Ivanov, and R. J. Bartlett, J. Chem. Phys. 116, 4415 (2002).

R. Pollet, A. Savin, T. Leininger, and H. Stoll, J. Chem. Phys. 116, 1250 (2002). 
153 P. Mori-Sanchez, Q. Wu, and W. Yang, J. Chem. Phys. 123, 62204 (2005).

154 L. A. Curtiss, K. Raghavachari, P. C. Redfern, and J. A. Pople, J. Chem. Phys. 106, 1063 (1997).

155 B. J. Lynch and D. G. Truhlar, J. Phys. Chem. A 107, 8996 (2003), 108, 1460(E) (2004).

156 S. Grimme, Angew. Chem. Int. Ed. 45, 4460 (2006).

157 M. O. Sinnokrot, E. F. Valeev, and C. D. Sherrill, J. Am. Chem. Soc. 124, 10887 (2002).

158 NIST Standard Reference Database. See, (http://webbook.nist.gov/chemistry/). 
Table 1: Optimized parameters in the M06-L Methods.

\begin{tabular}{|c|c|c|c|c|c|c|}
\hline \multirow{2}{*}{ parameters } & \multicolumn{6}{|c|}{ M06-L } \\
\hline & $a_{i}$ & $c_{C \alpha \beta, i}$ & $c_{C \sigma \sigma, i}$ & $d_{i}$ & $d_{C \alpha \beta, i}$ & $d_{C \sigma \sigma, i}$ \\
\hline 0 & $3.987756 \mathrm{E}-01$ & $6.042374 \mathrm{E}-01$ & $5.349466 \mathrm{E}-01$ & $6.012244 \mathrm{E}-01^{a}$ & $3.957626 \mathrm{E}-01^{a}$ & $4.650534 \mathrm{E}-01$ \\
\hline 1 & $2.548219 \mathrm{E}-01$ & $1.776783 \mathrm{E}+02$ & $5.396620 \mathrm{E}-01$ & $4.748822 \mathrm{E}-03$ & $-5.614546 \mathrm{E}-01$ & $1.617589 \mathrm{E}-01$ \\
\hline 2 & 3.923994E-01 & $-2.513252 \mathrm{E}+02$ & $-3.161217 \mathrm{E}+01$ & $-8.635108 \mathrm{E}-03$ & $1.403963 \mathrm{E}-02$ & $1.833657 \mathrm{E}-01$ \\
\hline 3 & $-2.103655 \mathrm{E}+00$ & $7.635173 \mathrm{E}+01$ & $5.149592 \mathrm{E}+01$ & $-9.308062 \mathrm{E}-06$ & $9.831442 \mathrm{E}-04$ & $4.692100 \mathrm{E}-04$ \\
\hline 4 & $-6.302147 \mathrm{E}+00$ & $-1.255699 \mathrm{E}+01$ & $-2.919613 \mathrm{E}+01$ & $4.482811 \mathrm{E}-05$ & $-3.577176 \mathrm{E}-03$ & $-4.990573 \mathrm{E}-03$ \\
\hline 5 & $1.097615 \mathrm{E}+01$ & & & & & \\
\hline 6 & $3.097273 \mathrm{E}+01$ & & & & & \\
\hline 7 & $-2.318489 \mathrm{E}+01$ & & & & & \\
\hline 8 & $-5.673480 \mathrm{E}+01$ & & & & & \\
\hline 9 & $2.160364 \mathrm{E}+01$ & & & & & \\
\hline 10 & $3.421814 \mathrm{E}+01$ & & & & & \\
\hline 11 & $-9.049762 \mathrm{E}+00$ & & & & & \\
\hline
\end{tabular}

${ }^{a}$ determined by a constraint, as explained in Section IV.C. 
Table 2: Tested Density Functionals

\begin{tabular}{|c|c|c|c|c|c|c|c|c|c|c|}
\hline \multirow{2}{*}{ Method } & \multirow{2}{*}{ Year } & \multirow{2}{*}{$\operatorname{Ref}(\mathrm{s})$} & \multicolumn{4}{|c|}{ exchange } & \multicolumn{4}{|c|}{ correlation } \\
\hline & & & $\rho_{\sigma}, \nabla \rho_{\sigma}$ & $X$ & $\tau ?$ & UEG ? & $\rho_{\sigma}, \nabla \rho_{\sigma}$ & $\tau_{\sigma} ?$ & SCorF? & UEG ? \\
\hline \multicolumn{11}{|l|}{ Local } \\
\hline BP86 & 1988 & 5, & $\mathrm{~B} 88$ & 0 & no & yes & P86 & no & no & yes \\
\hline BLYP & 1988 & 7,8 & B88 & 0 & no & yes & LYP & no & yes & no \\
\hline BB95 & 1996 & 7,11 & B88 & 0 & no & yes & B95 & yes & yes & yes \\
\hline G96LYP & 1996 & 8,45 & G96 & 0 & no & yes & LYP & no & yes & no \\
\hline $\mathrm{PBE}$ & 1996 & 46 & PBE & 0 & no & yes & PBE & no & no & yes \\
\hline $\mathrm{mPWPW}^{a}$ & 1998 & 47,16 & $\mathrm{mPW}$ & 0 & no & yes & PW91 & no & no & yes \\
\hline $\mathrm{VSXC}^{b}$ & 1998 & 12 & VSXC & 0 & yes & no & VSXC & yes & yes & no \\
\hline НCTH & 1998 & 48 & НCTH & 0 & no & no & НСТН & no & no & no \\
\hline OLYP & 2001 & 41 & OPTX & 0 & no & no & LYP & no & yes & no \\
\hline$\tau-\mathrm{HCTH}$ & 2002 & 49 & $\tau-\mathrm{HCTH}$ & 0 & yes & no & $\tau$-HCTH & no & no & no \\
\hline TPSS & 2003 & 13 & TPSS & 0 & yes & yes & TPSS & yes & yes & yes \\
\hline M06-L & 2006 & 17 & M06-L & 0 & yes & yes & M06-L & yes & yes & yes \\
\hline \multicolumn{11}{|l|}{ Nonlocal } \\
\hline B3LYP & 1994 & $7,14,50$ & B88 & 20 & no & no & LYP & no & yes & no \\
\hline TPSSh & 2003 & 51 & TPSS & 10 & yes & yes & TPSS & yes & yes & yes \\
\hline M05 & 2005 & 44 & M05 & 28 & yes & yes & M05 & yes & yes & yes \\
\hline
\end{tabular}

${ }^{a}$ also called mPWPW91

$b$ also called VS98. 
Table 3: Mean errors ${ }^{a}(\mathrm{kcal} / \mathrm{mol}$ for ionization potentials (IP), electron affinities (EA) and Proton Affinities (PA) and kcal/mol per bond for atomization energies (AE))

\begin{tabular}{|c|c|c|c|c|c|c|c|c|c|}
\hline \multirow{2}{*}{ Method } & \multicolumn{2}{|c|}{ AE109 } & \multicolumn{2}{|c|}{ IP13 } & \multicolumn{2}{|c|}{ EA13 } & \multicolumn{2}{|c|}{ PA8 } & \multirow{2}{*}{ TMUH } \\
\hline & MSEPB & MUEPB & MSE & MUE & MSE & MUE & MSE & MUE & \\
\hline \multicolumn{10}{|l|}{ Local } \\
\hline VSXC & -0.18 & 0.57 & 2.31 & 3.29 & 0.22 & 2.80 & 1.83 & 1.98 & 1.10 \\
\hline OLYP & -0.05 & 0.86 & -1.50 & 2.66 & 3.23 & 3.57 & 2.30 & 2.30 & 1.35 \\
\hline M06-L & 0.05 & 0.85 & 0.76 & 3.09 & 2.96 & 3.84 & 2.01 & 2.06 & 1.39 \\
\hline TPSS & 0.63 & 1.03 & 1.80 & 3.11 & 0.51 & 2.31 & 2.67 & 2.67 & 1.43 \\
\hline$\tau$-НСТН & -0.08 & 0.85 & 3.66 & 4.32 & -0.88 & 2.61 & 3.17 & 3.17 & 1.46 \\
\hline НCТН & -0.31 & 1.05 & 4.85 & 5.46 & -2.37 & 3.75 & 2.69 & 2.69 & 1.79 \\
\hline BLYP & -0.47 & 1.49 & -0.41 & 4.87 & -0.11 & 2.63 & -0.69 & 1.53 & 1.90 \\
\hline mPWPW & 1.72 & 2.01 & 2.93 & 4.15 & -1.56 & 2.26 & 0.88 & 1.49 & 2.20 \\
\hline G96LYP & -1.39 & 1.96 & -1.12 & 4.64 & 1.33 & 2.93 & 0.81 & 1.40 & 2.26 \\
\hline BB95 & 2.18 & 2.34 & -0.55 & 3.34 & 0.21 & 1.99 & 0.23 & 1.65 & 2.36 \\
\hline PBE & 2.80 & 3.03 & 2.11 & 3.58 & -1.20 & 2.22 & 0.04 & 1.35 & 2.91 \\
\hline BP86 & 3.55 & 3.65 & 4.48 & 5.38 & -4.23 & 4.23 & 0.35 & 1.37 & 3.73 \\
\hline \multicolumn{10}{|l|}{ Nonlocal } \\
\hline M05 & -0.01 & 0.53 & -0.41 & 2.87 & 2.81 & 2.96 & 1.20 & 2.16 & 1.06 \\
\hline B3LYP & -0.69 & 0.91 & 3.58 & 4.72 & -1.51 & 2.29 & 0.18 & 1.02 & 1.39 \\
\hline TPSSh & -0.12 & 0.98 & 1.96 & 3.17 & 1.40 & 2.81 & 2.78 & 2.78 & 1.45 \\
\hline Average & 0.51 & 1.48 & 1.63 & 3.91 & 0.05 & 2.88 & 1.36 & 1.98 & 1.85 \\
\hline
\end{tabular}


${ }^{a}$ MUEPB denotes mean unsigned error (MUE) per bond. MSE denotes mean signed error. TMUE denotes total MUE and it is defined as: $\mathrm{TMUE}=[\mathrm{MUEPB} \times 109+\mathrm{MUE}(\mathrm{IP}) \times 13+\mathrm{MUE}(\mathrm{AE}) \times 13+\mathrm{MUE}(\mathrm{PA}) * 8] / 143$.

${ }^{b}$ In all tables where the last row is "Average", it is the average of that column for all functionals in the table. 
Table 4: Mean errors for thermochemical kinetics $a, b, c$

\begin{tabular}{|c|c|c|c|c|c|c|c|c|c|c|}
\hline \multirow{2}{*}{ Methods } & \multicolumn{2}{|c|}{ Heavy AtomTransfer (12) } & \multicolumn{2}{|c|}{ Nuc. Sub. (16) ${ }^{d}$} & \multicolumn{2}{|c|}{ Unimol. (10) $)^{e}$} & \multicolumn{2}{|c|}{ Hydrogen Transfer (38) } & \multirow{2}{*}{ AMUE } & \multirow{2}{*}{ MMUE } \\
\hline & MSE & MUE & MSE & MUE & MSE & MUE & MSE & MUE & & \\
\hline \multicolumn{11}{|l|}{ Local } \\
\hline M06-L & -5.58 & 5.93 & -3.58 & 3.58 & 0.04 & 1.86 & -4.14 & 4.16 & 3.02 & 3.88 \\
\hline НCTH & -8.84 & 8.84 & -2.71 & 2.71 & -0.75 & 2.20 & -5.41 & 5.47 & 3.36 & 4.81 \\
\hline VSXC & -7.44 & 7.44 & -5.30 & 5.30 & -0.91 & 2.40 & -4.86 & 4.87 & 3.45 & 5.00 \\
\hline OLYP & -11.23 & 11.23 & -2.73 & 2.73 & -1.92 & 2.53 & -5.59 & 5.63 & 3.92 & 5.53 \\
\hline$\tau$-НCTH & -9.21 & 9.21 & -5.71 & 5.71 & -1.04 & 2.82 & -6.82 & 6.87 & 4.04 & 6.15 \\
\hline G96LYP & -13.03 & 13.03 & -5.80 & 5.80 & -2.86 & 3.04 & -6.25 & 6.26 & 4.75 & 7.03 \\
\hline BB95 & -13.88 & 13.88 & -6.36 & 6.36 & -3.22 & 3.40 & -8.14 & 8.14 & 5.29 & 7.94 \\
\hline MPWPW & -14.10 & 14.10 & -7.45 & 7.45 & -2.67 & 3.10 & -8.43 & 8.43 & 5.38 & 8.27 \\
\hline BLYP & -14.66 & 14.66 & -8.40 & 8.40 & -3.38 & 3.51 & -7.52 & 7.52 & 5.67 & 8.52 \\
\hline TPSS & -14.65 & 14.65 & -7.75 & 7.75 & -3.84 & 4.04 & -7.71 & 7.71 & 5.72 & 8.54 \\
\hline PBE & -14.93 & 14.93 & -6.97 & 6.97 & -2.94 & 3.35 & -9.32 & 9.32 & 5.65 & 8.64 \\
\hline BP86 & -15.51 & 15.51 & -6.91 & 6.91 & -3.41 & 3.87 & -9.16 & 9.16 & 6.05 & 8.86 \\
\hline \multicolumn{11}{|l|}{ Nonlocal } \\
\hline M05 & -2.84 & 3.79 & 0.00 & 0.80 & 0.69 & 2.24 & -1.20 & 1.93 & 2.06 & 2.19 \\
\hline B3LYP & -8.49 & 8.49 & -3.25 & 3.25 & -1.42 & 2.02 & -4.13 & 4.23 & 3.10 & 4.50 \\
\hline TPSSh & -11.51 & 11.51 & -5.78 & 5.78 & -2.94 & 3.23 & -5.97 & 5.97 & 4.57 & 6.62 \\
\hline Average & -11.06 & 11.15 & -5.25 & 5.30 & -2.04 & 2.91 & -6.31 & 6.38 & 4.40 & 6.43 \\
\hline
\end{tabular}


$b$ AMUE is defined in as: $\mathrm{AMUE}=[\mathrm{MUE}(\Delta \mathrm{E}, 38)+\mathrm{MMUE}] / 2$, where $\mathrm{MUE}(\Delta \mathrm{E}, 38)$ is the mean unsigned error for the energy of reactions for the 38 reactions involved in this table. AMUE is one measure of the quality of a method for kinetics.

${ }^{c}$ The QCISD/MG3 geometries and MG3S basis set are used for calculations in this table.

$d$ 'Nuc. Sub.' denotes nucleophilic substitution reactions.

$e^{e}$ This denotes unimolecular and association reactions. 
Table 5: Mean Errors for Noncovalent Databases $(\mathrm{kcal} / \mathrm{mol})^{a}, b, c$

\begin{tabular}{|c|c|c|c|c|c|c|c|c|c|c|c|c|c|c|c|c|}
\hline \multirow{3}{*}{ Method } & \multicolumn{3}{|c|}{ HB6/04 } & \multicolumn{3}{|c|}{ СТ7/04 } & \multicolumn{3}{|c|}{ DI6/04 } & \multicolumn{3}{|c|}{ WI7/05 } & \multicolumn{3}{|c|}{ PPS5/05 } & \multirow{3}{*}{ MMMUE } \\
\hline & \multicolumn{2}{|c|}{ MUE } & \multirow{2}{*}{ MMUE } & \multicolumn{2}{|c|}{ MUE } & \multirow{2}{*}{ MMUE } & \multicolumn{2}{|c|}{ MUE } & \multirow{2}{*}{ MMUE } & \multicolumn{2}{|c|}{ MUE } & \multirow{2}{*}{ MMUE } & \multicolumn{2}{|c|}{ MUE } & \multirow{2}{*}{ MMUE } & \\
\hline & no-cp & $\mathrm{cp}$ & & no-cp & $\mathrm{cp}$ & & no-cp & $\mathrm{cp}$ & & no-cp & $\mathrm{cp}$ & & no-cp & $\mathrm{cp}$ & & \\
\hline \multicolumn{17}{|l|}{ Local } \\
\hline M06-L & 0.21 & 0.51 & 0.36 & 1.80 & 1.41 & 1.61 & 0.32 & 0.32 & 0.32 & 0.19 & 0.13 & 0.16 & 0.17 & 0.42 & 0.29 & 0.55 \\
\hline PBE & 0.45 & 0.32 & 0.39 & 2.95 & 2.63 & 2.79 & 0.46 & 0.40 & 0.43 & 0.13 & 0.15 & 0.14 & 1.86 & 2.09 & 1.97 & 1.14 \\
\hline$\tau$-НСТН & 0.67 & 1.12 & 0.90 & 1.77 & 1.47 & 1.62 & 0.50 & 0.53 & 0.52 & 0.22 & 0.23 & 0.22 & 2.46 & 2.72 & 2.59 & 1.17 \\
\hline TPSS & 0.45 & 0.82 & 0.63 & 2.20 & 1.86 & 2.03 & 0.52 & 0.56 & 0.54 & 0.19 & 0.26 & 0.22 & 2.53 & 2.78 & 2.66 & 1.22 \\
\hline mPWPW & 0.57 & 0.96 & 0.77 & 2.25 & 1.89 & 2.07 & 0.56 & 0.59 & 0.57 & 0.24 & 0.32 & 0.28 & 2.69 & 2.96 & 2.83 & 1.30 \\
\hline НСТН & 1.68 & 2.12 & 1.90 & 1.31 & 1.22 & 1.26 & 0.55 & 0.71 & 0.63 & 0.28 & 0.21 & 0.25 & 3.06 & 3.35 & 3.21 & 1.45 \\
\hline BP86 & 0.72 & 1.10 & 0.91 & 2.03 & 1.73 & 1.88 & 0.66 & 0.76 & 0.71 & 0.65 & 0.74 & 0.70 & 3.22 & 3.45 & 3.33 & 1.51 \\
\hline BLYP & 1.18 & 1.56 & 1.37 & 1.67 & 1.42 & 1.54 & 1.00 & 1.18 & 1.09 & 0.45 & 0.53 & 0.49 & 3.58 & 3.79 & 3.69 & 1.63 \\
\hline BB95 & 1.83 & 2.21 & 2.02 & 1.48 & 1.27 & 1.38 & 1.18 & 1.35 & 1.27 & 0.57 & 0.66 & 0.62 & 2.96 & 3.18 & 3.07 & 1.67 \\
\hline VSXC & 0.45 & 0.79 & 0.62 & 2.84 & 2.53 & 2.68 & 1.10 & 1.02 & 1.06 & 0.94 & 0.90 & 0.92 & 6.75 & 6.58 & 6.66 & 2.39 \\
\hline OLYP & 3.60 & 4.09 & 3.84 & 1.57 & 1.58 & 1.57 & 2.35 & 2.53 & 2.44 & 0.38 & 0.44 & 0.41 & 4.72 & 4.96 & 4.84 & 2.62 \\
\hline G96LYP & 2.95 & 3.30 & 3.13 & 1.20 & 1.28 & 1.24 & 2.57 & 2.74 & 2.65 & 1.37 & 1.47 & 1.42 & 5.19 & 5.41 & 5.30 & 2.75 \\
\hline \multicolumn{17}{|l|}{ Nonlocal } \\
\hline M05 & 0.58 & 0.53 & 0.55 & 0.68 & 0.30 & 0.49 & 0.23 & 0.24 & 0.23 & 0.14 & 0.06 & 0.10 & 1.12 & 1.34 & 1.23 & 0.52 \\
\hline TPSSh & 0.41 & 0.80 & 0.60 & 1.44 & 1.16 & 1.30 & 0.49 & 0.58 & 0.54 & 0.18 & 0.26 & 0.22 & 2.46 & 2.72 & 2.59 & 1.05 \\
\hline B3LYP & 0.60 & 0.93 & 0.76 & 0.71 & 0.54 & 0.63 & 0.78 & 0.94 & 0.86 & 0.31 & 0.39 & 0.35 & 2.95 & 3.17 & 3.06 & 1.13 \\
\hline Average & 1.09 & 1.41 & 1.25 & 1.73 & 1.49 & 1.61 & 0.88 & 0.96 & 0.92 & 0.42 & 0.45 & 0.43 & 3.00 & 3.20 & 3.10 & 1.46 \\
\hline
\end{tabular}


$a$ MUE denotes mean unsigned error (MUE). MMUE $=[$ MUE(cp) + MUE(no-cp) $] / 2$, and MMMUE $=[M M U E(H B)+$ MMUE $(C T)+M M U E(D I)+$ MMUE(WI)+ MMUE(PPS)]/5; HB: hydrogen bonding; CT: charge transfer; DI: dipole interaction; WI: weak interaction; PPS: $\pi-\pi$ stacking

$b$ We use "no-cp" to denote the calculation without the counterpoise correction for the BSSE, and use "cp" to denote the calculation with the counterpoise correction for the BSSE

${ }^{c}$ The MG3S basis set is used for calculations in this table. 
Table 6. Mean errors for the S22 noncovalent database of biological importance.

\begin{tabular}{lcccc}
\hline Method & MMUE-HB $^{a}$ & MMUE-D $^{b}$ & MMUE-Mix $^{c}$ & MMMUE $^{d}$ \\
\hline Local & & & & \\
M06-L & 0.82 & 0.76 & 0.72 & 0.77 \\
PBE & 1.13 & 4.53 & 1.66 & 2.44 \\
TPSS & 1.59 & 5.62 & 2.36 & 3.19 \\
mPWPW & 1.86 & 5.95 & 2.55 & 3.45 \\
$\tau$-HCTH & 1.76 & 6.75 & 2.67 & 3.73 \\
BP86 & 2.02 & 6.41 & 2.94 & 3.79 \\
BB95 & 3.54 & 5.43 & 2.97 & 3.98 \\
HCTH & 3.29 & 6.57 & 2.48 & 4.11 \\
BLYP & 7.43 & 3.45 & 4.60 \\
G96LYP & 2.94 & 10.55 & 5.50 & 7.05 \\
OLYP & 5.11 & 10.43 & 4.94 & 7.19 \\
VSXC & 15.12 & 5.18 & \\
Nonlocal & 5.98 & & & 1.83 \\
M05 & 1.27 & 3.16 & 1.09 & 3.01 \\
TPSSh & & 5.42 & 2.22 & 3.54 \\
B3LYP & 1.26 & 6.22 & 2.64 & 3.99 \\
Average & 1.41 & & 2.89 & \\
\hline$a$ Seven hydr & 1.77 & 6.69 & & \\
\hline
\end{tabular}

${ }^{a}$ Seven hydrogen bonded complexes.

${ }^{b}$ Eight complexes dominated by dispersion-like interactions, including $\pi-\pi$ stacking.

${ }^{c}$ Seven mixed complexes, e. g., benzene ${ }^{\cdots} \mathrm{H}_{2} \mathrm{O}$.

$d$ Average of these previous columns. 
Table 7. MUE (kcal/mol) for the TMAE9/05, MLBE21/05, and 3dTMRE18/06 databases ${ }^{a}$

\begin{tabular}{|c|c|c|c|c|c|c|c|}
\hline \multirow{2}{*}{ Method } & \multicolumn{2}{|c|}{ TMAE9/05 } & \multicolumn{2}{|c|}{ MLBE21/05 } & \multicolumn{2}{|c|}{ 3dTMRE18/06 } & \multirow{2}{*}{ MMUE } \\
\hline & MSE & MUE & MSE & MUE & MSE & MUE & \\
\hline \multicolumn{8}{|l|}{ Local } \\
\hline M06-L & 0.2 & 4.9 & 4.7 & 5.4 & 3.8 & 6.9 & 5.7 \\
\hline G96LYP & 0.2 & 4.8 & 7.0 & 7.7 & 4.4 & 10.3 & 7.6 \\
\hline OLYP & -2.8 & 7.7 & 4.9 & 6.3 & 2.9 & 9.0 & 7.7 \\
\hline TPSS & -1.3 & 6.1 & 7.4 & 7.9 & 7.9 & 10.2 & 8.1 \\
\hline BLYP & 4.8 & 5.3 & 9.0 & 9.6 & 5.5 & 10.6 & 8.5 \\
\hline VSXC & 5.5 & 10.2 & 6.3 & 6.6 & 8.2 & 8.9 & 8.6 \\
\hline mPWPW & 0.5 & 6.4 & 10.2 & 10.6 & 9.1 & 10.3 & 9.1 \\
\hline НСТН & 11.3 & 11.9 & 7.3 & 7.6 & 4.5 & 8.0 & 9.2 \\
\hline BP86 & 5.6 & 7.6 & 11.8 & 12.2 & 8.9 & 10.3 & 10.0 \\
\hline PBE & 3.9 & 7.7 & 11.7 & 12.1 & 10.3 & 10.8 & 10.2 \\
\hline BB95 & 9.5 & 9.5 & 12.6 & 12.9 & 12.4 & 12.5 & 11.7 \\
\hline$\tau$-НСТН & 20.2 & 20.2 & 9.0 & 9.2 & 11.6 & 11.9 & 13.8 \\
\hline \multicolumn{8}{|l|}{ Nonlocal } \\
\hline M05 & -3.0 & 6.9 & -0.7 & 5.5 & -3.0 & 7.8 & 6.8 \\
\hline TPSSh & -11.0 & 11.0 & 2.1 & 5.5 & 1.0 & 9.7 & 8.7 \\
\hline B3LYP & -16.7 & 16.7 & -0.6 & 6.0 & -6.6 & 12.0 & 11.6 \\
\hline Average & 1.8 & 9.1 & 6.9 & 8.3 & 5.4 & 10.0 & 9.1 \\
\hline
\end{tabular}


Table 8. Alkyl Bond Dissociation Energies $\left(D_{\mathrm{e}}, \mathrm{kcal} / \mathrm{mol}\right)^{a, b}$

\begin{tabular}{|c|c|c|c|c|c|c|}
\hline \multirow{2}{*}{ Method } & \multicolumn{2}{|c|}{$\mathrm{R}-\mathrm{CH} 3$} & \multicolumn{2}{|c|}{ R-OCH3 } & \multirow{2}{*}{ MSE } & \multirow{2}{*}{ MUE } \\
\hline & $\mathrm{R}=\mathrm{Me}$ & $\mathrm{R}=i-\mathrm{Pr}$ & $\mathrm{R}=\mathrm{Me}$ & $\mathrm{R}=i-\mathrm{Pr}$ & & \\
\hline Exp. & 97.39 & 95.00 & 89.79 & 91.51 & & \\
\hline \multicolumn{7}{|l|}{ Local } \\
\hline BB95 & 98.35 & 90.15 & 87.79 & 83.69 & -3.43 & 3.91 \\
\hline PBE & 96.79 & 89.65 & 87.24 & 84.08 & -3.98 & 3.98 \\
\hline M06-L & 96.32 & 88.96 & 84.49 & 81.75 & -5.54 & 5.54 \\
\hline BP86 & 94.62 & 87.19 & 85.49 & 82.10 & -6.07 & 6.07 \\
\hline mPWPW & 94.58 & 87.22 & 85.26 & 81.87 & -6.19 & 6.19 \\
\hline VSXC & 90.11 & 87.22 & 81.16 & 83.72 & -7.87 & 7.87 \\
\hline$\tau-\mathrm{HCTH}$ & 93.43 & 84.43 & 84.69 & 79.51 & -7.91 & 7.91 \\
\hline НСТН & 92.70 & 84.04 & 82.95 & 78.07 & -8.98 & 8.98 \\
\hline TPSS & 90.48 & 83.74 & 82.36 & 79.54 & -9.39 & 9.39 \\
\hline OLYP & 92.09 & 83.35 & 81.43 & 76.34 & -10.12 & 10.12 \\
\hline BLYP $^{c}$ & 90.31 & 82.64 & 81.09 & 77.50 & -10.53 & 10.53 \\
\hline G96LYP & 89.01 & 80.68 & 79.64 & 75.40 & -12.24 & 12.24 \\
\hline \multicolumn{7}{|l|}{ Nonlocal } \\
\hline M05 & 94.47 & 86.99 & 86.32 & 82.77 & -5.79 & 5.79 \\
\hline $\mathrm{B}^{2} \mathrm{LYP}^{c}$ & 91.58 & 85.01 & 82.58 & 80.06 & -8.62 & 8.62 \\
\hline TPSSh & 90.47 & 84.12 & 82.08 & 79.62 & -9.35 & 9.35 \\
\hline Average & & & & & -7.73 & 7.76 \\
\hline
\end{tabular}

${ }^{a}$ The B3LYP/6-31G(d) geometries are used in all calculations in this table.

${ }^{b}$ All DFT calculations in this table use the $6-311+\mathrm{G}(3 \mathrm{df}, 2 \mathrm{p})$ basis set.

${ }^{c}$ Data for these methods are taken from a paper by Izgorodina et al. ${ }^{75}$ 
Table 9. Results for $\pi$ systems $^{a}$

\begin{tabular}{|c|c|c|c|c|c|c|c|}
\hline \multirow{2}{*}{ Method } & \multicolumn{2}{|c|}{$\pi \mathrm{IE} 3$} & \multicolumn{2}{|c|}{ PA-P5 } & \multicolumn{2}{|c|}{ PA-SB5 } & \multirow{2}{*}{ MMUE } \\
\hline & MSE & MUE & MSE & MUE & MSE & MUE & \\
\hline \multicolumn{8}{|l|}{ Local } \\
\hline PBE & 8.8 & 8.8 & 4.2 & 4.2 & 4.5 & 4.8 & 5.9 \\
\hline BB95 & 8.7 & 8.7 & 4.4 & 4.4 & 4.5 & 4.9 & 6.0 \\
\hline BP86 & 8.8 & 8.8 & 4.8 & 4.8 & 4.7 & 4.9 & 6.2 \\
\hline BLYP & 8.7 & 8.7 & 4.9 & 5.5 & 4.3 & 4.8 & 6.3 \\
\hline M06-L & 5.4 & 5.4 & 7.8 & 7.8 & 6.1 & 6.1 & 6.4 \\
\hline mPWPW & 8.8 & 8.8 & 5.5 & 5.5 & 5.7 & 5.7 & 6.6 \\
\hline G96LYP & 8.7 & 8.7 & 6.5 & 6.5 & 6.1 & 6.1 & 7.1 \\
\hline TPSS & 8.4 & 8.4 & 8.4 & 8.4 & 7.4 & 7.4 & 8.1 \\
\hline НCТН & 8.4 & 8.4 & 7.8 & 7.8 & 8.3 & 8.3 & 8.2 \\
\hline OLYP & 8.7 & 8.7 & 8.3 & 8.3 & 7.7 & 7.7 & 8.2 \\
\hline VSXC & 8.4 & 8.4 & 8.3 & 8.3 & 8.1 & 8.1 & 8.3 \\
\hline$\tau$-НСТН & 8.6 & 8.6 & 8.8 & 8.8 & 8.6 & 8.6 & 8.7 \\
\hline \multicolumn{8}{|l|}{ Nonlocal } \\
\hline M05 & 1.8 & 1.8 & 7.9 & 7.9 & 5.5 & 5.5 & 5.1 \\
\hline B3LYP & 6.2 & 6.2 & 5.8 & 5.8 & 5.9 & 5.9 & 6.0 \\
\hline TPSSh & 7.2 & 7.2 & 8.6 & 8.6 & 7.8 & 7.8 & 7.9 \\
\hline Average & 7.7 & 7.7 & 6.8 & 6.8 & 6.3 & 6.4 & 7.0 \\
\hline
\end{tabular}

${ }^{a}$ The MG3S basis set and MP2/6-31+G(d,p) geometries are employed. 
Table 10. Metal atom excitation energy $(\mathrm{kcal} / \mathrm{mol})^{a}$

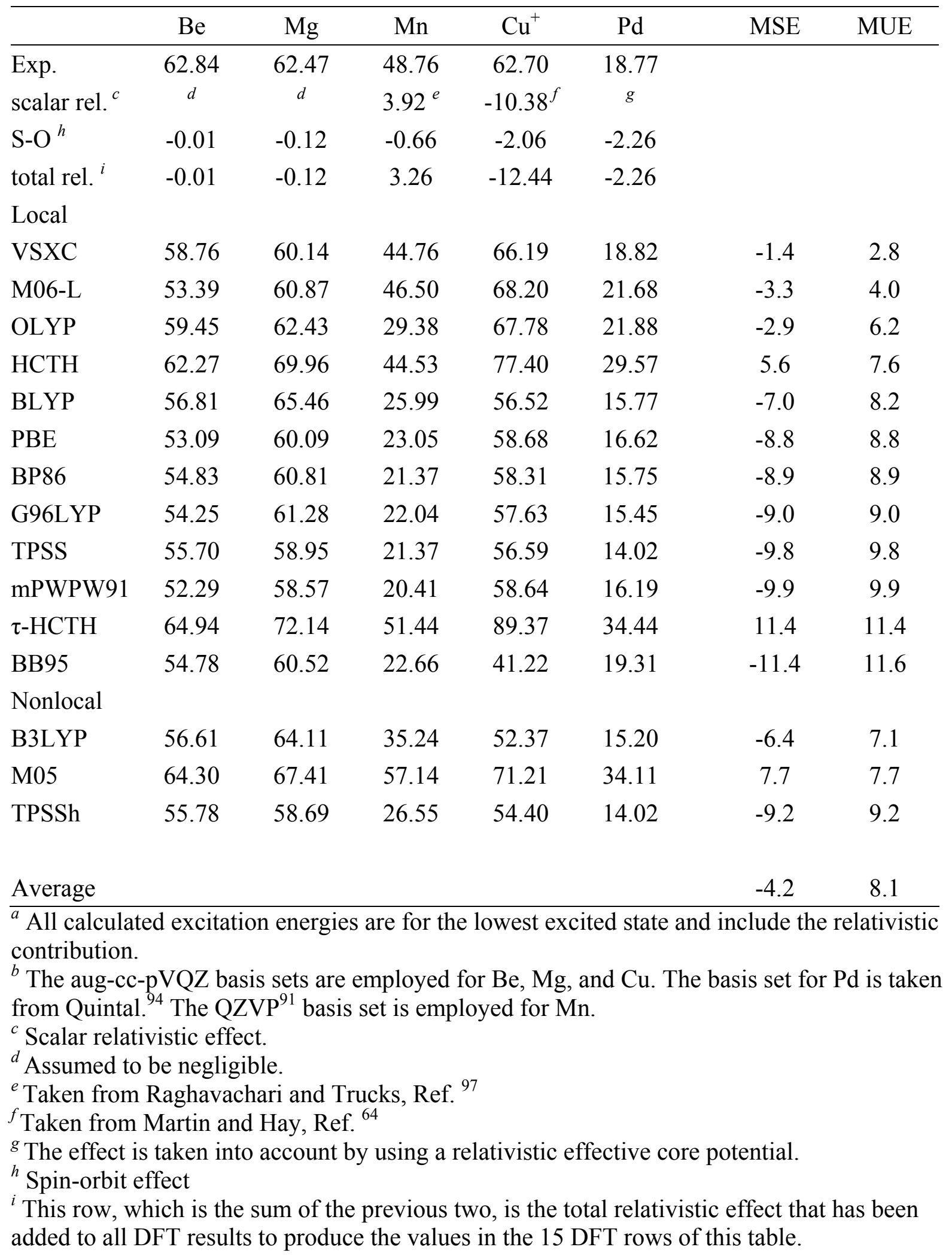


Table 11. overall results

\begin{tabular}{|c|c|c|c|c|c|c|c|c|c|c|}
\hline Method & $\begin{array}{c}\text { Thermocehmistry } \\
\text { TMUE }\end{array}$ & $\begin{array}{l}\text { Barriers } \\
\text { MMUE }\end{array}$ & $\begin{array}{l}\text { Noncovalent } \\
\text { MMMUE }\end{array}$ & $\begin{array}{l}\text { Biological } \\
\text { MMUE }\end{array}$ & $\begin{array}{c}\text { TM } \\
\text { MMUE }\end{array}$ & $\begin{array}{l}\text { BDE } \\
\text { MUE }\end{array}$ & $\begin{array}{l}\pi \text {-system } \\
\text { MMUE }\end{array}$ & $\begin{array}{l}\text { Excitation } \\
\text { MUE }\end{array}$ & $\mathrm{CMUE}^{a}$ & $\mathrm{WMUE}^{b}$ \\
\hline \multicolumn{11}{|l|}{ Local } \\
\hline M06-L & 1.39 & 3.88 & 0.55 & 0.77 & 5.71 & 5.54 & 6.42 & 3.95 & 3.53 & 3.34 \\
\hline НСТН & 1.89 & 4.81 & 1.26 & 4.11 & 9.19 & 8.98 & 8.17 & 7.56 & 5.75 & 5.63 \\
\hline PBE & 3.09 & 8.64 & 1.14 & 2.44 & 10.23 & 3.98 & 5.93 & 8.80 & 5.53 & 5.64 \\
\hline TPSS & 1.52 & 8.54 & 1.22 & 3.19 & 8.07 & 9.39 & 8.08 & 9.78 & 6.22 & 5.86 \\
\hline mPWPW & 2.33 & 8.27 & 1.30 & 3.45 & 9.12 & 6.19 & 6.64 & 9.89 & 5.90 & 5.87 \\
\hline VSXC & 1.17 & 5.00 & 2.39 & 7.19 & 8.56 & 7.87 & 8.30 & 2.79 & 5.41 & 5.93 \\
\hline$\tau-\mathrm{HCTH}$ & 1.54 & 6.15 & 1.20 & 3.73 & 13.78 & 7.91 & 8.65 & 11.36 & 6.79 & 6.20 \\
\hline BB95 & 2.50 & 7.94 & 1.67 & 3.98 & 11.65 & 3.91 & 6.00 & 11.63 & 6.16 & 6.24 \\
\hline BLYP & 2.02 & 8.52 & 1.63 & 4.60 & 8.50 & 10.53 & 6.34 & 8.19 & 6.29 & 6.33 \\
\hline BP86 & 3.96 & 8.86 & 1.51 & 3.79 & 10.03 & 6.07 & 6.16 & 8.89 & 6.16 & 6.62 \\
\hline OLYP & 1.43 & 5.53 & 2.62 & 7.12 & 7.69 & 10.12 & 8.24 & 6.20 & 6.12 & 6.62 \\
\hline G96LYP & 2.40 & 7.03 & 2.75 & 7.05 & 7.61 & 12.24 & 7.09 & 8.98 & 6.89 & 7.51 \\
\hline \multicolumn{11}{|l|}{ Nonlocal } \\
\hline M05 & 1.12 & 2.19 & 0.52 & 1.83 & 6.75 & 5.79 & 5.10 & 7.06 & 3.79 & 3.44 \\
\hline B3LYP & 1.47 & 4.50 & 1.13 & 3.54 & 11.57 & 8.62 & 5.98 & 7.73 & 5.57 & 5.22 \\
\hline TPSSh & 1.53 & 6.62 & 1.05 & 3.01 & 8.73 & 9.35 & 7.87 & 9.22 & 5.92 & 5.52 \\
\hline Average & 1.85 & 6.43 & 1.46 & 3.99 & 9.15 & 7.77 & 7.00 & 8.13 & 5.72 & 5.72 \\
\hline
\end{tabular}

${ }^{a}$ CMUE denotes composite MUE, and it is the average of the eight previous columns.

${ }^{b}$ WMUE denotes weighted MUE; see Section V.H for the definition of WMUE. 
Table 12. Performance for the prediction of bond lengths $(\AA)$ in the MGBL19 and MLBL13/05 databases $^{a}$

\begin{tabular}{|c|c|c|c|c|c|c|c|c|}
\hline \multicolumn{2}{|c|}{ Bond lengths } & Exp. $^{b}$ & M06-L & VSXC & B3LYP & TPSS & PBE & BLYP \\
\hline \multicolumn{9}{|c|}{ MGBL19 database } \\
\hline \multicolumn{2}{|l|}{$\mathrm{H}_{2}$} & 0.741 & 0.743 & 0.741 & 0.743 & 0.743 & 0.751 & 0.747 \\
\hline \multicolumn{2}{|l|}{$\mathrm{CH}_{4}$} & 1.086 & 1.086 & 1.087 & 1.088 & 1.092 & 1.096 & 1.094 \\
\hline \multicolumn{2}{|l|}{$\mathrm{NH}_{3}$} & 1.012 & 1.012 & 1.011 & 1.013 & 1.019 & 1.021 & 1.021 \\
\hline \multicolumn{2}{|l|}{$\mathrm{H}_{2} \mathrm{O}$} & 0.957 & 0.958 & 0.958 & 0.961 & 0.968 & 0.969 & 0.971 \\
\hline \multicolumn{2}{|l|}{$\mathrm{HF}$} & 0.917 & 0.917 & 0.919 & 0.922 & 0.929 & 0.930 & 0.933 \\
\hline \multicolumn{2}{|l|}{$\mathrm{CO}$} & 1.128 & 1.128 & 1.133 & 1.125 & 1.135 & 1.137 & 1.137 \\
\hline \multicolumn{2}{|l|}{$\mathrm{N}_{2}$} & 1.098 & 1.096 & 1.098 & 1.091 & 1.100 & 1.103 & 1.103 \\
\hline \multicolumn{2}{|l|}{$\mathrm{F}_{2}$} & 1.412 & 1.405 & 1.414 & 1.396 & 1.415 & 1.412 & 1.432 \\
\hline \multirow[t]{2}{*}{$\mathrm{C}_{2} \mathrm{H}_{2}$} & $\mathrm{C}-\mathrm{C}$ & 1.203 & 1.198 & 1.203 & 1.196 & 1.202 & 1.207 & 1.206 \\
\hline & $\mathrm{C}-\mathrm{H}$ & 1.063 & 1.062 & 1.063 & 1.062 & 1.065 & 1.071 & 1.067 \\
\hline \multirow[t]{2}{*}{$\mathrm{HCN}$} & $\mathrm{C}-\mathrm{H}$ & 1.065 & 1.067 & 1.067 & 1.066 & 1.070 & 1.075 & 1.072 \\
\hline & $\mathrm{C}-\mathrm{N}$ & 1.153 & 1.150 & 1.154 & 1.146 & 1.155 & 1.158 & 1.157 \\
\hline \multirow[t]{2}{*}{$\mathrm{H}_{2} \mathrm{CO}$} & $\mathrm{C}-\mathrm{H}$ & 1.102 & 1.111 & 1.109 & 1.106 & 1.110 & 1.117 & 1.114 \\
\hline & $\mathrm{C}-\mathrm{O}$ & 1.203 & 1.195 & 1.204 & 1.199 & 1.208 & 1.209 & 1.212 \\
\hline \multicolumn{2}{|l|}{$\mathrm{CO}_{2}$} & 1.160 & 1.159 & 1.165 & 1.160 & 1.169 & 1.171 & 1.173 \\
\hline \multirow[t]{2}{*}{$\mathrm{N}_{2} \mathrm{O}$} & $\mathrm{N}-\mathrm{N}$ & 1.128 & 1.129 & 1.131 & 1.121 & 1.134 & 1.138 & 1.139 \\
\hline & $\mathrm{N}-\mathrm{O}$ & 1.184 & 1.178 & 1.184 & 1.184 & 1.191 & 1.190 & 1.198 \\
\hline \multicolumn{2}{|l|}{$\mathrm{OH}$} & 0.970 & 0.971 & 0.972 & 0.974 & 0.982 & 0.983 & 0.985 \\
\hline \multicolumn{2}{|l|}{$\mathrm{Cl}_{2}$} & 1.988 & 1.980 & 2.012 & 2.016 & 2.016 & 2.011 & 2.046 \\
\hline \multicolumn{2}{|l|}{$\mathrm{MSE}^{c}$} & & -0.0014 & 0.0029 & -0.0024 & 0.0070 & 0.0094 & 0.0125 \\
\hline \multicolumn{2}{|l|}{ MUE $^{d}$} & & 0.0030 & 0.0031 & 0.0055 & 0.0071 & 0.0094 & 0.0125 \\
\hline \multicolumn{9}{|c|}{ MLBL13/05 database } \\
\hline \multicolumn{2}{|l|}{$\mathrm{AgH}$} & 1.618 & 1.644 & 1.630 & 1.637 & 1.634 & 1.627 & 1.634 \\
\hline \multicolumn{2}{|l|}{$\mathrm{BeO}$} & 1.331 & 1.321 & 1.345 & 1.321 & 1.336 & 1.340 & 1.340 \\
\hline \multicolumn{2}{|l|}{$\mathrm{CoH}$} & 1.531 & 1.538 & 1.528 & 1.532 & 1.530 & 1.526 & 1.529 \\
\hline \multicolumn{2}{|l|}{$\mathrm{CoO}^{+}$} & 1.646 & 1.637 & 1.643 & 1.636 & 1.631 & 1.627 & 1.644 \\
\hline $\mathrm{FeH}$ & & 1.610 & 1.584 & 1.579 & 1.573 & 1.571 & 1.570 & 1.572 \\
\hline $\mathrm{FeO}$ & & 1.616 & 1.611 & 1.628 & 1.612 & 1.606 & 1.606 & 1.621 \\
\hline $\mathrm{FeS}$ & & 2.013 & 1.998 & 2.021 & 2.028 & 2.011 & 2.011 & 2.030 \\
\hline $\mathrm{LiCl}$ & & 2.021 & 2.025 & 2.042 & 2.024 & 2.030 & 2.028 & 2.034 \\
\hline $\mathrm{LiO}$ & & 1.689 & 1.695 & 1.719 & 1.690 & 1.701 & 1.704 & 1.705 \\
\hline $\mathrm{MgO}$ & & 1.749 & 1.733 & 1.751 & 1.738 & 1.745 & 1.749 & 1.755 \\
\hline $\mathrm{RhC}$ & & 1.613 & 1.616 & 1.622 & 1.608 & 1.623 & 1.621 & 1.633 \\
\hline VO & & 1.589 & 1.583 & 1.594 & 1.580 & 1.590 & 1.585 & 1.598 \\
\hline VS & & 2.048 & 2.056 & 2.072 & 2.058 & 2.054 & 2.050 & 2.066 \\
\hline $\operatorname{MSE}^{c}$ & & & -0.003 & 0.008 & -0.003 & -0.001 & -0.002 & 0.007 \\
\hline MUE $^{d}$ & & & 0.011 & 0.013 & 0.010 & 0.010 & 0.010 & 0.013 \\
\hline & & & & oth data & & & & \\
\hline $\mathrm{AMUE}^{e}$ & & & 0.007 & 0.008 & 0.008 & 0.009 & 0.010 & 0.013 \\
\hline
\end{tabular}


${ }^{a}$ The MG3S basis set is employed for all functionals in this table.

${ }^{b}$ From Ref. ${ }^{48}$.

${ }^{c}$ MSE denotes mean signed error.

${ }^{d}$ MUE denotes mean unsigned error.

${ }^{e}$ AMUE is the average of the two MUEs in this table. 
Table 13. Performance for the prediction of harmonic frequencies $\left(\mathrm{cm}^{-1}\right)^{a}$

\begin{tabular}{|c|c|c|c|c|c|c|c|c|}
\hline Molecule & Mode & Best est. ${ }^{b}$ & VSXC & B3LYP & M06-L & TPSS & PBE & BLYP \\
\hline $\mathrm{H}_{2}$ & $\omega_{1}$ & 4401 & 4412 & 4421 & 4324 & 4419 & 4319 & 4349 \\
\hline \multirow[t]{4}{*}{$\mathrm{CH}_{4}$} & $\omega_{1}$ & 1367 & 1320 & 1345 & 1334 & 1343 & 1289 & 1313 \\
\hline & $\omega_{2}$ & 1583 & 1550 & 1562 & 1564 & 1561 & 1512 & 1527 \\
\hline & $\omega_{3}$ & 3026 & 3034 & 3034 & 3042 & 3003 & 2976 & 2967 \\
\hline & $\omega_{4}$ & 3157 & 3156 & 3135 & 3180 & 3105 & 3089 & 3061 \\
\hline \multirow[t]{4}{*}{$\mathrm{NH}_{3}$} & $\omega_{1}$ & 3478 & 3489 & 3483 & 3492 & 3406 & 3401 & 3374 \\
\hline & $\omega_{2}$ & 1084 & 1025 & 1017 & 1073 & 1054 & 1010 & 1011 \\
\hline & $\omega_{3}$ & 3597 & 3618 & 3603 & 3627 & 3523 & 3524 & 3489 \\
\hline & $\omega_{4}$ & 1684 & 1671 & 1669 & 1688 & 1667 & 1624 & 1634 \\
\hline \multirow[t]{3}{*}{$\mathrm{H}_{2} \mathrm{O}$} & $\omega_{1}$ & 1648 & 1642 & 1631 & 1665 & 1632 & 1597 & 1599 \\
\hline & $\omega_{2}$ & 3832 & 3827 & 3819 & 3860 & 3719 & 3719 & 3676 \\
\hline & $\omega_{3}$ & 3942 & 3937 & 3922 & 3976 & 3824 & 3825 & 3779 \\
\hline $\mathrm{HF}$ & $\omega_{1}$ & 4138 & 4102 & 4096 & 4169 & 3993 & 3987 & 3938 \\
\hline $\mathrm{CO}$ & $\omega_{1}$ & 2170 & 2165 & 2214 & 2204 & 2140 & 2130 & 2116 \\
\hline $\mathrm{N}_{2}$ & $\omega_{1}$ & 2359 & 2394 & 2445 & 2407 & 2365 & 2347 & 2329 \\
\hline $\mathrm{F}_{2}$ & $\omega_{1}$ & 917 & 974 & 1045 & 979 & 1001 & 992 & 955 \\
\hline \multirow[t]{5}{*}{$\mathrm{C}_{2} \mathrm{H}_{2}$} & $\omega_{1}$ & 624 & 616 & 665 & 660 & 615 & 607 & 603 \\
\hline & $\omega_{2}$ & 747 & 760 & 765 & 797 & 763 & 733 & 733 \\
\hline & $\omega_{3}$ & 2008 & 2039 & 2067 & 2062 & 2028 & 2009 & 2003 \\
\hline & $\omega_{4}$ & 3415 & 3420 & 3409 & 3401 & 3380 & 3342 & 3339 \\
\hline & $\omega_{5}$ & 3495 & 3518 & 3509 & 3504 & 3478 & 3440 & 3435 \\
\hline \multirow[t]{3}{*}{$\mathrm{HCN}$} & $\omega_{1}$ & 727 & 753 & 764 & 789 & 747 & 729 & 724 \\
\hline & $\omega_{2}$ & 2127 & 2154 & 2199 & 2175 & 2136 & 2119 & 2110 \\
\hline & $\omega_{3}$ & 3443 & 3437 & 3439 & 3415 & 3400 & 3360 & 3356 \\
\hline \multirow[t]{6}{*}{$\mathrm{H}_{2} \mathrm{CO}$} & $\omega_{1}$ & 2937 & 2857 & 2888 & 2847 & 2851 & 2798 & 2791 \\
\hline & $\omega_{2}$ & 1778 & 1794 & 1817 & 1853 & 1768 & 1764 & 1738 \\
\hline & $\omega_{3}$ & 1544 & 1518 & 1531 & 1524 & 1518 & 1479 & 1490 \\
\hline & $\omega_{4}$ & 1188 & 1185 & 1200 & 1196 & 1178 & 1150 & 1154 \\
\hline & $\omega_{5}$ & 3012 & 2906 & 2943 & 2895 & 2899 & 2842 & 2834 \\
\hline & $\omega_{6}$ & 1269 & 1246 & 1264 & 1257 & 1245 & 1219 & 1226 \\
\hline \multirow[t]{3}{*}{$\mathrm{CO}_{2}$} & $\omega_{1}$ & 673 & 668 & 679 & 690 & 652 & 647 & 640 \\
\hline & $\omega_{2}$ & 1354 & 1345 & 1371 & 1385 & 1325 & 1322 & 1306 \\
\hline & $\omega_{3}$ & 2397 & 2401 & 2408 & 2473 & 2358 & 2359 & 2319 \\
\hline
\end{tabular}




\begin{tabular}{ccccccccc}
$\mathrm{N}_{2} \mathrm{O}$ & $\omega_{1}$ & 596 & 617 & 620 & 638 & 599 & 597 & 579 \\
& $\omega_{2}$ & 1298 & 1322 & 1326 & 1356 & 1290 & 1300 & 1257 \\
& $\omega_{3}$ & 2282 & 2320 & 2340 & 2367 & 2269 & 2279 & 2219 \\
\multirow{2}{*}{ all } & MSE $^{c}$ & MSE & -3 & 10 & 16 & -29 & -52 & -64 \\
& MUE $^{d}$ & MUE & 24 & 31 & 39 & 39 & 56 & 67 \\
$<2000 \mathrm{~cm}^{-1}$ & MSE $^{c}$ & MSE & -1 & 8 & 11 & -48 & -71 & -91 \\
& MUE $^{d}$ & MUE & 24 & 32 & 45 & 54 & 71 & 91 \\
& MSE $^{c}$ & MSE & -4 & 11 & 22 & -7 & -30 & -35 \\
& MUE $^{d}$ & MUE & 23 & 30 & 33 & 22 & 40 & 39 \\
\hline
\end{tabular}

${ }^{a}$ The MG3S basis set is employed for all functionals in this table. Although all values are rounded to the nearest integer in this table, mean errors were computed from unrounded data.

${ }^{b}$ From Ref. ${ }^{81}$

${ }^{c}$ MSE denotes mean signed error.

${ }^{d}$ MUE denotes mean unsigned error. 
Table 14. Comparison to a fifth-rung functional ${ }^{a}$

\begin{tabular}{lcc}
\hline & M06-L & B2-PLYP \\
\hline MUE of AE6 & $3.8^{b}$ & $3.4^{b}$ \\
MUE of BH6 & $4.3^{b}$ & $1.9^{b}$ \\
${\text { UE of } D_{\mathrm{e}} \text { of benzene dimer }}^{c}$ & 0.4 & 2.5 \\
UE of the isomerization energy of octane $^{d}$ & 1.3 & $5.4^{e}$ \\
& & \\
cost & 324 & 3906 \\
\hline
\end{tabular}

${ }^{a}$ MUE is mean unsigned error in $\mathrm{kcal} / \mathrm{mol}$; UE is unsigned error in $\mathrm{kcal} / \mathrm{mol}$. Cost is measured as the computer time (in arbitrary units) for a single-point energy calculation of the benzene dimer (sandwich) with the $6-311+\mathrm{G}(2 \mathrm{df}, 2 \mathrm{p})$ basis set on a single processor of an Altix 3700 computer.

${ }^{b}$ The MG3S basis set and QCISD/MG3 geometries were employed for calculations on the AE6 and BH6 databases. To convert the AE6 results in this table to a per bond basis (which was not done), one would divide by 4.83 .

${ }^{c}$ The best estimate $D_{\mathrm{e}}$ for the parallel displaced configuration is $2.8 \mathrm{kcal} / \mathrm{mol} ;{ }^{157} D_{\mathrm{e}}$ for M06-L is $2.4 \mathrm{kcal} / \mathrm{mol}$. The UE for the B2-PLYP method is taken from Ref. ${ }^{150}$

${ }^{d}$ The best estimate is $1.9 \mathrm{kcal} / \mathrm{mol}$ for the zero-point exclusive energy of $n$-octane minus that of tetramethylbutane; ${ }^{156,158} \mathrm{M} 06$-L gives $0.6 \mathrm{kcal} / \mathrm{mol}$, whereas B2-PLYP predicts a value of $-3.5 \mathrm{kcal} / \mathrm{mol}$. ${ }^{156}$ The basis set used for the octane isomerization calculation is MG3S for M06$\mathrm{L}$ and the level is cQZV3P//MP2/TZV(d,p) for B2-PLYP.

${ }^{e}$ Taken from Ref. ${ }^{156}$ 